\title{
Design, Preparation, and Characterization of Dioscin Nanosuspensions and Evaluation of Their Protective Effect against Carbon Tetrachloride-Induced Acute Liver Injury in Mice
}

\author{
Hong-Ye JU, Kun-Xia Hu, Guo-Wang Zhao, Zhi-Shu Tang, and Xiao Song $(\mathbb{D}$ \\ School of Pharmacy, Shaanxi University of Chinese Medicine, Xianyang 712046, China \\ Correspondence should be addressed to Xiao Song; song-xiaoyao@163.com
}

Received 11 October 2018; Revised 20 December 2018; Accepted 17 July 2019; Published 14 November 2019

Guest Editor: Maria Rosaria Lauro

Copyright (c) 2019 Hong-Ye Ju et al. This is an open access article distributed under the Creative Commons Attribution License, which permits unrestricted use, distribution, and reproduction in any medium, provided the original work is properly cited.

\begin{abstract}
The purpose of this study was to prepare a dioscin nanosuspension (Dio-NS) that has a better distance and high solubility for oral administration and to evaluate its hepatoprotective effects. Optimal primary manufacture parameters, including shear time, shear speed, emulation temperature, pressure, and cycles of homogenization, were determined by single-factor experiments. The concentrations of dioscin, SDS, and soybean lecithin were optimized using the central composite design-response surface method, and their effects on the mean particle size (MPS) and particle size distribution of Dio-NS were investigated. Characterization of the Dio-NS formulations included examinations of the surface morphology and physical status of dioscin in Dio-NS, the stability of Dio-NS at different temperatures, in vitro solubility, and liver protective effect in vivo. Under optimal conditions, Dio-NS had an MPS of $106.72 \mathrm{~nm}$, polydispersity index of 0.221 , and zeta potential of $-34.27 \mathrm{mV}$. Furthermore, the proportion of dioscin in DioNS was approximately $21.26 \%$. The observation of particles with a spherical shape and the disappearance of crystalline peaks indicated that the physical and chemical properties of Dio-NS were altered. Furthermore, we observed that the dissolution of DioNS was superior to that of a physical mixture and Dio-GZF. Moreover, Dio-NS was demonstrated to have a protective effect against $\mathrm{CCl}_{4}$-induced acute liver damage in mice that was equivalent to that of silymarin (a positive control drug) at the same dose. The good hepatoprotective effect of our Dio-NS preparation can provide a theoretical basis for investigating its absorption mechanisms in the body.
\end{abstract}

\section{Introduction}

Dioscin (Figure 1), also known as Paris polyphylla saponin III, is a steroidal saponin [1]that can be extracted from the Chinese yam (Dioscorea paniculata) and other plants in the Dioscoreaceae family [2]. Dioscin has several important pharmacological activities, including antitumor [3], antiinflammatory [4], antiliver damnification [5], antihepatic fibrosis [6,7], antihyperlipidemic, and antioxidative properties. Furthermore, the compound has therapeutic potential in metabolic diseases and can also be decomposed into diosgenin, which has been an important basic raw material for the production of steroid hormone drugs [8].Meanwhile, it has also been established that there is potential to develop the pharmaceutic value of dioscin. In addition, some reports have been found on dioscin toxicology. It has no adverse effect on the acute toxicological studies at a dose of $562.5 \mathrm{mg} /$ $\mathrm{kg} / \mathrm{d}$ in mice $[9,10]$. However, on the subchronic toxicological assessment, it was verified as the NOAEL (no-observed-adverse-effect level) at a dose of $300 \mathrm{mg} / \mathrm{kg} /$ day in female rats and in male rats was marked as the LOAEL (lowest-observed-adverse-effect level) at the same dose [11]. So, rational drug use is the key to lower ADR.

In fact, dioscin has a notable disadvantage, in that when the valid route fails, the probability of a new established route occurring via secondary chain scission is large. Its poor solubility and slow dissolution rate limit its absorption, thus affecting its efficacy.

Poor solubilities and dissolution rates are key factors affecting the absorption of drugs in the body. Thus, several techniques have been devised in order to overcome these undesirable properties, including micronization [12], 


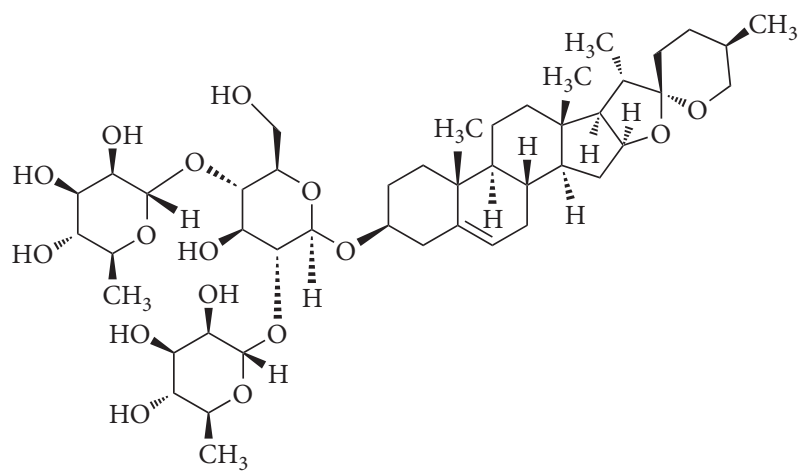

FIgURE 1: The chemical structure of dioscin.

solubilization, and salt formation [13]. However, these techniques are only partially effective. The advent of nanotechnology, which can produce nanoscale particles with novel functional properties, offers a potential solution to the aforementioned drawbacks. Nanotechnology has, for example, been used to enhance the bioavailability of certain antibiotics [14] and has also been applied to produce different targeted drugs for the treatment of different diseases [15-17], and various nanosuspensions have been successfully applied $[18,19]$. Nanoparticles can also be prepared using a variety of different processes, including reverse solvent, homogenization pressure, milling, and the production of self-nanoemulsifying self-nanosuspensions [20].

Diseases of the liver, including hepatitis, hepatapostema, hepatocirrhosis, and liver cancer, are common and often life-threatening. Carbon tetrachloride $\left(\mathrm{CCl}_{4}\right)[21,22]$, paracetamol [23, 24], lipopolysaccharide [25, 26], and certain other chemicals can also cause acute liver damage, and consequently, a large number of drugs are used for the treatment of hepatic disorders [27]. It was confirmed that dioscin has significant hepatoprotective effect against $\mathrm{CCl} 4$ induced liver injury in mice, and the cellular mechanisms of this effect are likely to be associated with inhibition of lipid peroxidation, inflammatory cytokines, necrosis, and apoptosis. Thus, in the present study, we formulated a dioscin nanosuspension (Dio-NS) using reverse solvent precipitation combined with high-pressure homogenization and compared its efficacy with that of the commercial drug silymarin in protecting mice from acute hepatic damage induced by $\mathrm{CCl}_{4}$. We assumed that the Dio-NS formulation would enhance the solubility of dioscin and thus increase the efficacy of this compound in protecting against liver injury.

\section{Methods}

2.1. Materials. Dioscin was purchased from Nanjing Spring and Autumn Biological Engineering (Nanjing, China) with the purity of $>99 \%$. Soybean lecithin, mannitol, poloxamer188, Tween-80, PVP K30, sodium cholate, sodium alkyl sulfate twelve (SDS), anhydrous ethanol, lactose, glucose, sucrose, D-sorbitol, silymarin, 4\% paraformaldehyde solution, methanol, and acetonitrile were all of chromatographic grade, and the other reagents were all of analytical grade. AST and ALT kits were purchased from Nanjing Jiancheng
Institute of Biotechnology (Nanjing, China). TNF- $\alpha$, IL- $1 \beta$, IL-6, MDA, SOD, and GSH-Px kits were purchased from Shanghai Elisa Biotech Co., Ltd.

2.2. Preparation of Dio-NS. Dioscin was dissolved in ethanol as a solvent and dispersed for $15 \mathrm{~min}$ in a KQ-3-DE ultrasonic bath (Kunshan, China). In the next emulsification process, ethanol was used as the organic phase of the emulsion. The solution was rapidly added dropwise to double-distilled water-saturated ethanol together with sodium alkyl sulfate twelve and soybean lecithin as excipients that can be used to improve the stability of emulsions, commixing using magnetic stirrer (HJ-6B, Changzhou, China). A microemulsion was obtained by high-speed shearing (FJ-200, ShenZhen, China). The microemulsion preparation was then homogenized to produce a nanoemulsion via high-pressure homogenization (AH-BASICI, ATS Engineering Inc., Canada). An EYELA N-1300 rotary evaporator was used to remove the ethanol (LangYi, Shanghai, China) at an evaporation temperature of $40^{\circ} \mathrm{C}$, thereby yielding the Dio-NS preparation. In this study, the optimal process conditions were determined on the basis of single-factor experimental results. All the preparation steps are shown in Figure 2.

2.3. Preparation of a Physical Mixture. The desired dosage of Dio-NS was obtained by dissolving in water and freezedrying for $12 \mathrm{~h}$ to yield an NS-A physical mixture.

2.4. Screening of Excipients. Eleven groups were examined to select the best accessories that have a minimum size and powder dispersion index.

2.5. Single-Factor Experiment. In the single-factor experiment, particle size and multiple dispersion index were taken as indicators to determine optimal preparation parameters, including shear time, shear speed, emulation temperature, pressure, and cycles of homogenization.

2.6. Optimization of the Response Surface of the Star Design. On the basis of the results of the single-factor experiment and the feasibility of preparing nanosuspensions at the highest or lowest level, we selected the level of each factor and the star response surface design software and determined the best experimental results.

2.7. Lyophilization. The Dio-NS preparation was lyophilized using a VaCo-5 freeze-drying apparatus (Zirbus, Germany) to obtain dry powder with good physicochemical stability. In this study, a single-factor method was used to select optimal conditions, and the best freeze-drying protectant was selected. The results are shown in Table 1 . The content of freeze-drying protectant ranged from $2 \%$ to $10 \%$. The levels are shown in Table 2. 


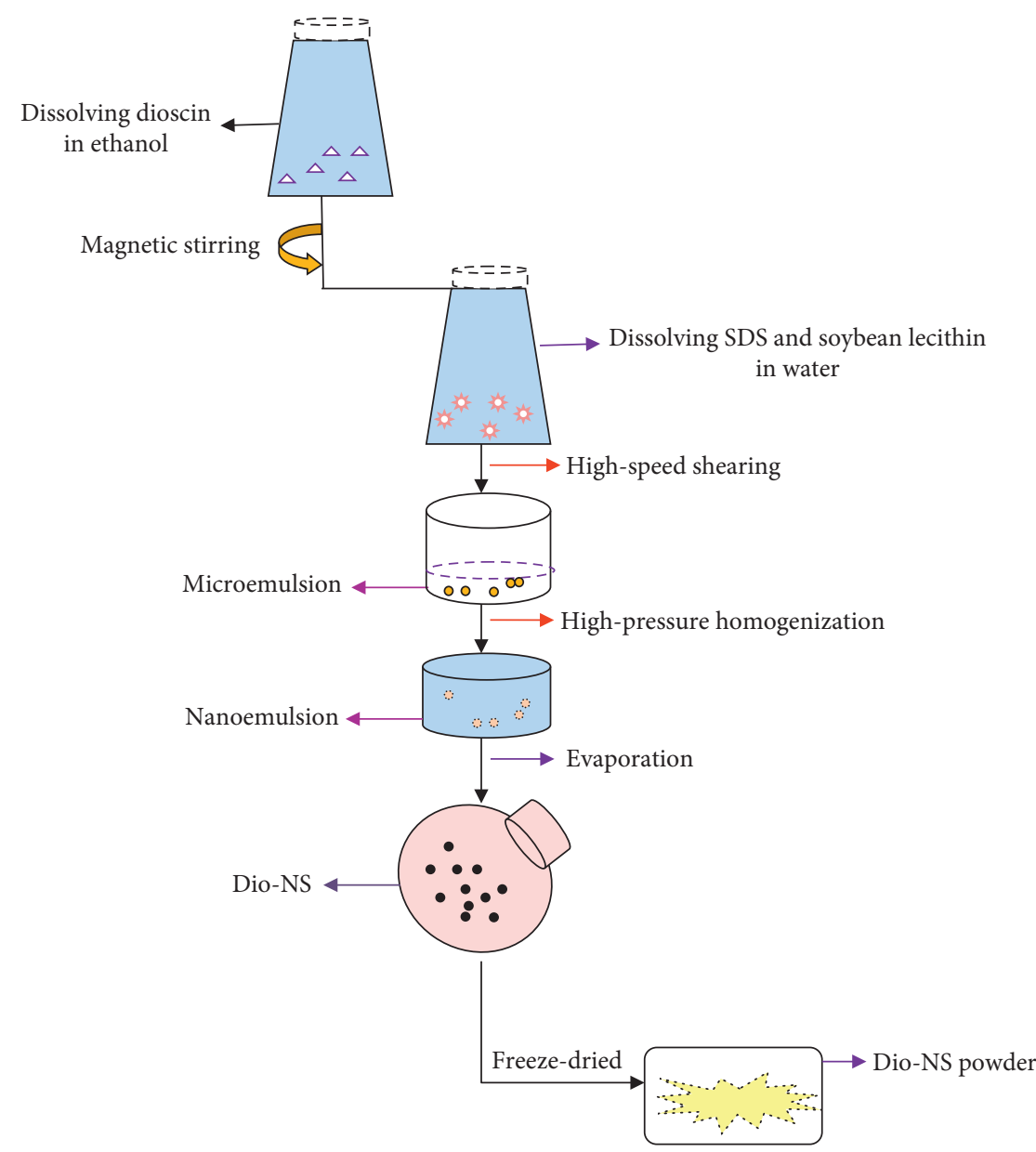

FIGURE 2: A flow diagram showing the steps involved in the preparation of Dio-NS.

TABLE 1: Screening of freeze-drying protectants.

\begin{tabular}{|c|c|c|c|c|}
\hline Type & Sensory evaluation & Size $(\mathrm{nm})$ & PDI & Zeta $(\mathrm{mv})$ \\
\hline Lactose & $\begin{array}{l}\text { White powder: shows collapse and shrinkage, uneven } \\
\text { color, and poor dispersion. }\end{array}$ & $123.5 \pm 0.61$ & $0.278 \pm 0.003$ & $-23.2 \pm 2.25$ \\
\hline Glucose & $\begin{array}{l}\text { White powder: shows collapse and shrinkage, uneven } \\
\text { color, and poor dispersion }\end{array}$ & $2200 \pm 521.85$ & $1 \pm 0.001$ & $-42.3 \pm 1.86$ \\
\hline Sucrose & $\begin{array}{c}\text { White powder: shows collapse and shrinkage, uneven } \\
\text { color, and poor dispersion. }\end{array}$ & $1195.7 \pm 382.27$ & $0.586 \pm 0.075$ & $-51.4 \pm 5.41$ \\
\hline D-sorbitol & $\begin{array}{l}\text { White powder: shows collapse and shrinkage, uneven } \\
\text { color, and poor dispersion. }\end{array}$ & $172.4 \pm 6.99$ & $0.271 \pm 0.023$ & $-52.6 \pm 2.68$ \\
\hline Mannitol & $\begin{array}{c}\text { White powder: shows no collapse or shrinkage, } \\
\text { uniform color, and good dispersion. }\end{array}$ & $223 \pm 1.56$ & $0.273 \pm 0.055$ & $-59.1 \pm 0.38$ \\
\hline
\end{tabular}

$(n=3$, Mean \pm SEM $)$.

2.8. Particle Size and Zeta Potential. The mean particle size (MPS), particle size distribution (PSD), and zeta potential of the formulation were determined using a Malvern particle size meter. Samples were prepared by dissolution of Dio-NS in deionized water, and each property was measured 3 times.

2.9. Morphological Observations (SEM). The morphology of particles was determined by scanning electron microscopy (SEM) (MERLIN Compact, German). Samples were affixed to aluminum stubs using a double-sided carbon tape and sputter-coated with gold under an argon atmosphere.
2.10. Transmission Electron Microscopy (TEM). After 4 types of samples had been vortexed for $2 \mathrm{~min}$, they were dripped onto a copper sheet of a transmission electron microscope (JEOL, Japan), and the excess moisture was dried using a filter paper. Images of the samples were observed on the perspective electron microscope.

2.11. X-Ray Powder Diffraction. The crystalline state of substances was typically determined by X-ray powder diffraction. Diffraction patterns of the Dio-NS and other auxiliary material were determined using a Bruker D8 
TABLE 2: Screening for the dosage of freeze-drying protectants.

\begin{tabular}{lccc}
\hline Ratio (\%) & Size $(\mathrm{nm})$ & PDI & Zeta $(\mathrm{mv})$ \\
\hline \multirow{3}{*}{2} & 433.4 & 0.620 & -40.8 \\
& 463.2 & 0.553 & -41.8 \\
& 441.3 & 0.540 & -42.8 \\
3 & 229.2 & 0.391 & -53.4 \\
& 231.6 & 0.402 & -58.5 \\
& 229.5 & 0.416 & -57.4 \\
5 & 196.4 & 0.285 & -35.3 \\
& 194.8 & 0.275 & -36.9 \\
7 & 194.9 & 0.285 & -36.2 \\
& 173.8 & 0.234 & -53.6 \\
& 173.1 & 0.245 & -57.3 \\
8 & 172.7 & 0.239 & -58.0 \\
& 187.4 & 0.223 & -58.0 \\
& 182.6 & 0.245 & -57.1 \\
10 & 184.3 & 0.248 & -56.0 \\
& 205.5 & 0.242 & -53.9 \\
& 201.6 & 0.263 & -54.2 \\
& 207.1 & 0.272 & -56.3 \\
\hline
\end{tabular}

advance X-ray diffractometer (Bruker, Germany). A Cu line was used as the source of radiation, and standard runs were performed at a voltage of $40 \mathrm{kV}$, step length of $0.01^{\circ}$, current of $40 \mathrm{~mA}$, and a scanning rate of $0.1 \mathrm{~s} / \mathrm{step}$ over a 2 theta range of $5-90^{\circ}$.

2.12. Thermal Analysis. Individual samples were placed in different aluminum differential scanning calorimeter (DSC) pans (214 Polyma, Netzsch, Germany), which were heated to $200^{\circ} \mathrm{C}$ and $150^{\circ} \mathrm{C}$ for approximately $15 \mathrm{~min}$. Thereafter, the samples were quench-cooled in liquid nitrogen externally to the DSC instrument. DSC was implemented by returning the samples to a prerefrigerating room $\left(-50^{\circ} \mathrm{C}\right)$, and thermograms were recorded.

2.13. In Vitro Dissolution of Dio-NS. The Dio-NS powder and physical mixture were loaded into dialysis membranes, which were placed in constant-speed oscillators at constant temperature and oscillated for different times. Samples of Dio-NS obtained at different time points were analyzed by HPLC (Waters e2695, USA). The cumulative release rate was determined using the following equation:

$\mathrm{Q} \%($ cumulative release rate $)=\frac{\left(\mathrm{Q} t_{1}+\mathrm{Q} t_{2}+\cdots+\mathrm{Q} t_{n}\right)}{\mathrm{Q}} \times 100 \%$,

where $Q t_{1}, Q t_{2}, \ldots, Q t_{\mathrm{n}}$ is the content of dioscin dissolved in Dio-NS between time $t_{0}$ and $t_{1,2, \ldots, n}$.

2.14. Stability Study. The stability of the dioscin nanoscale suspension at temperatures of $4^{\circ} \mathrm{C}$ and $25^{\circ} \mathrm{C}$ was investigated over a period of 1 month, and the results are shown in Table 3.
TABLE 3: Stability of Dio-NS freeze-dried powder over a period of 2 months $(n=3)$.

\begin{tabular}{lccc}
\hline Time $(\mathrm{d})$ & Size $(\mathrm{nm})$ & PDI & Zeta $(\mathrm{mV})$ \\
\hline 0 & $173.2 \pm 0.56$ & $0.235 \pm 0.01$ & $-56.3 \pm 2.36$ \\
15 & $173.7 \pm 0.63$ & $0.237 \pm 0.21$ & $-56.54 \pm 2.66$ \\
30 & $173.9 \pm 0.75$ & $0.237 \pm 0.56$ & $-56.73 \pm 2.86$ \\
60 & $174.9 \pm 0.85$ & $0.239 \pm 0.46$ & $-63.43 \pm 1.26$ \\
\hline
\end{tabular}

\subsection{The Effects of Dio-NS on Liver Preservation}

2.15.1. Animals and Treatment. Kunming male mice (18$22 \mathrm{~g}$ ) were purchased from Chengdu Dashuo Biotechnology Co., Ltd. (Chendu, China.). The mice were acclimated for 1 week in a controlled environment at $25 \pm 2^{\circ} \mathrm{C}$ under a $12 \mathrm{~h}$ dark/light photoperiod. They were subsequently randomly divided into the following 6 groups each containing 8 animals: group 1 (normal control) and group 2 (model control) were orally administered water for 7 days; group 3 (positive control) received silymarin $(50 \mathrm{mg} / \mathrm{kg})$ for 7 days; and groups 4 to 6 (low-, medium-, and high-dose groups, respectively) were administered Dio-NS (25, 50, and $100 \mathrm{mg} /$ $\mathrm{kg}$, respectively) intragastrically. Two hours after the final administration, the animals in group 1 were injected intraperitoneally with pure olive oil, whereas mice in the other groups were treated with $0.2 \%(\mathrm{v} / \mathrm{v}) \mathrm{CCl}_{4}(10 \mathrm{~mL} / \mathrm{kg}$ body weight, i.p.; dissolved in olive oil) [28]. Thereafter, the mice were maintained with free access to water and were sacrificed $24 \mathrm{~h}$ later, at which time blood was collected for the preparation of serum. After killing the animals, the livers were immediately isolated and weighed to determine the liver index (liver index $=$ liver weight $/$ body weight $\times 100 \%$ ). A portion of each liver was fixed in $4 \%$ paraformaldehyde solution for pathological study, and the remainder along with the acquired serum samples were stored at $-80^{\circ} \mathrm{C}$ for subsequent studies. The entire process was performed on ice.

2.15.2. Serum Biochemistry Assays. The activities of ALT, AST, TNF- $\alpha$, IL- $1 \beta$, and IL- 6 in the serum were measured using commercial kits following the manufacturer's instructions.

2.15.3. Liver Lipid Peroxidation Assay. After saline was added to the appropriate liver tissue, the sample was placed into an automated tissue homogenizer (SCIENTZ-48, Ningbo, China) to prepare a $10 \%$ hepatic homogenate. Samples were processed using commercial kits according the manufacturer's instructions, and the levels of MDA, GSH$\mathrm{Px}$, and SOD in the liver homogenate were evaluated using a microplate reader.

2.15.4. Histopathological Examination. Fixed liver tissues were embedded in paraffin, from which $5-\mu \mathrm{m}$ sections were cut and placed on slides. The samples were stained with hematoxylin and eosin (H\&E) and then observed at $\times 400$ magnification. 
2.15.5. Statistical Analysis. SPSS version 19.0 statistical software was used to analyze all the data using a one-way ANOVA. Data are represented as mean \pm S.E.M. Differences between groups were considered significant at $p<0.01$ and $p<0.05$ levels.

\section{Results}

3.1. Evaluation of the Dio-NS Preparation. The results of stabilizer screening showed that different stabilizers had a considerable influence on the average particle size, polydispersity index, and system storage stability of drug suspensions [29](Table 4). On the premise of maintaining the same total amount, the combined use of different types of stabilizers effectively reduced the 3 qualitative indexes of drug suspension. In this study, we found that when the combined application of soybean lecithin and SDS was used as a stabilizer for the suspension system, the average size of the drug particles was small, the distribution was narrow, and the physical stability of the system was good. Therefore, we used soybean lecithin and SDS as stabilizers for Dio-NS. An SDS:lecithin ratio of $1: 1$ proved to be the optimal combination.

As shown in Figure 3, it is clear that temperature has little effect on emulsification. We also established that the minimum particle size and polydispersity index are obtained under the following conditions: a shear speed of 19,500 rpm, a shear time of $2 \mathrm{~min}$, a homogeneous pressure of $800 \mathrm{bar}$, and 7 cycles of homogenization. We thus obtained the optimal operation parameters (Table 5). Table 6 shows the results of 20-run experiments designed on the basis of 3 factors and 4 levels using Design-Expert 8.0.6 software. The results of a regression analysis are shown in equations (2) and (3):

$$
\begin{aligned}
Y= & +0.66-0.095 A-0.023 B-0.065 C+0.10 A B-0.033 A C \\
& +2.375 E-003 B C-0.13 A^{2}+0.030 B^{2}+0.047 C^{2}, \\
R= & 0.9411, P<0.0001 .
\end{aligned}
$$

$\mathrm{OD}=(d 1, d 2, \ldots, d k) 1^{K}$, where $K$ is the number of indices.

$$
\begin{aligned}
& d_{\text {min }}=\left(Y_{\max }-Y_{i}\right)\left(Y_{\max }-Y_{\min }\right), \\
& d_{\max }=\left(Y_{i}-Y_{\min }\right)\left(Y_{\max }-Y_{\min }\right) .
\end{aligned}
$$

Figure 4 shows the results of the interaction between 2 groups. For Dio-NS preparation with a content of $26.67 \%$ (w/w) dioscin, 20\% (w/w) SDS, and 53.33\% (w/w) soybean lecithin, we obtained a maximum OD of 0.868 , which was close to that predicted. As shown in Table 1, the diameter of Dio-NS dry powder particles, polydispersity index, and zeta potential were less than those obtained using other freezedrying protection agents. Furthermore, the powder showed no collapse or shrinkage, the color and luster were more uniform, and the preparation had good dispersion, and therefore, soybean lecithin and SDS were selected as the protectants for the dioscin freeze-dried powder.

It can be seen from Table 2 that the particle size obtained using mannitol in the aqueous phase was $7 \%$, and values for the polydispersity index and the zeta potential were the smallest recorded.

The size, zeta potential, and polydispersity index of the Dio-NS formulations are shown in Table 7. A particle size diagram and zeta potential are shown in Figures 5(a) and 5(b), respectively. A sharp peak of Dio-NS, which represents its size, was identified at approximately 106.72 \pm 8.90. Furthermore, the zeta potential of Dio-NS was $-34.27 \pm 2.91 \mathrm{mV}$, indicating the reasonable stability of the preparation.

\subsection{Characterization of Dio-NS}

3.2.1. Particle Size and Zeta Potential. The particle size and zeta potential of the optimum Dio-NS are given in Table 7.

3.2.2. Surface Morphology and Particle Size of Dio-NS. Transmission and scanning electron microscopy were applied to analyze the morphology and structure of the Dio-NS formulations. Dioscin has a tubular crystal structure (Figure 6(a)). Figure 6 shows that Dio-NS has a nearspheroid particle structure with a particle size of approximately $106 \mathrm{~nm}$. Figure 6(b) shows that the redispersibility of Dio-NS powder in purified water was also nearly globoid and that the particle size is somewhat larger at approximately $173 \mathrm{~nm}$.

The scanning electron microscopy images shown in Figure 7 show that dioscin raw material (A) is acicular with a larger particle size, whereas that with mannitol $B$ is an irregular prism, that with soybean lecithin (C) shows irregular lumps, and that with twelve alkyl sodium sulfate (D) is irregular spherical and loose with pores. Dio-NS nanoparticles (E) show the same shape as seen under transmission electron microscopy, and the morphology changes. As described above, these features indicate that the freeze-drying process has significant effect on particle size [30].

3.2.3. Physical Status of Dioscin in the Dio-NS. DSC thermograms of pure dioscin, SDS, soybean lecithin, mannitol, physical mixture, and freeze-dried and dry powder of DioNS are shown in Figure 8. The DSC thermograms of raw dioscin, mannitol, and SDS show a sharp endothermic peak at approximately $294-296^{\circ} \mathrm{C}, 166^{\circ} \mathrm{C}$, and $204-207^{\circ} \mathrm{C}$, respectively. A peak similar to that of pure dioscin was also observed in the thermogram of the physical mixture, indicating a weak or negligible influence. However, this peak was not present in the freeze-dried and dry Dio-NS preparations, which indicates that dioscin occurs in an amorphous form in Dio-NS.

The diffraction intensity and distribution of each crystal will have a special rule [31]. By using X-ray diffraction, we can analyze whether the crystalline form has changed in the preparation process. The diffraction peak of dioscin raw powder shown in Figure 9 indicates that it has a strong crystalline structure, whereas the diffraction peak of the excipient soybean lecithin indicates that its structure is essentially amorphous. The peaks of dioscin in the physical 
TABLE 4: Screening of stabilizers.

\begin{tabular}{|c|c|c|c|c|}
\hline Type & Content & MPS & PDI & Macrostability of the system \\
\hline F-68 & $0.5 \%$ & 145.17 & 0.227 & $\begin{array}{l}\text { The suspension is white and opaque, producing } \\
\text { flocculent precipitates and deepening the color of the } \\
\text { system. }\end{array}$ \\
\hline SDS & $0.5 \%$ & 125.47 & 0.196 & $\begin{array}{l}\text { The suspension is white and opaque and easy to } \\
\text { precipitate. It can be dispersed into an original } \\
\text { emulsion. }\end{array}$ \\
\hline PVP K30 & $0.5 \%$ & 91 & 0.301 & $\begin{array}{c}\text { The suspension is white and opaque, and it produces } \\
\text { microprecipitates, which can be dispersed into an } \\
\text { original emulsion. }\end{array}$ \\
\hline Tween-80 & $0.5 \%$ & 108.8 & 0.316 & $\begin{array}{l}\text { The suspension is white and opaque. It is easy to } \\
\text { precipitate. It cannot be dispersed into an original } \\
\text { emulsion. }\end{array}$ \\
\hline Soybean lecithin & $0.5 \%$ & 201 & 0.269 & $\begin{array}{c}\text { The suspension is white and opaque, and it produces } \\
\text { microprecipitates, which can be dispersed into an } \\
\text { original emulsion. }\end{array}$ \\
\hline Sodium cholate & $0.5 \%$ & 89.43 & 0.298 & $\begin{array}{c}\text { The suspension is white and opaque. It is easy to } \\
\text { precipitate. It cannot be dispersed into an original } \\
\text { emulsion. }\end{array}$ \\
\hline F-68+SDS & $0.25 \%+0.25 \%$ & 175.23 & 0.294 & $\begin{array}{c}\text { The suspension is white and opaque, and it produces } \\
\text { microprecipitates, which can be dispersed into an } \\
\text { original emulsion. }\end{array}$ \\
\hline PVP K30 + SDS & $0.25 \%+0.25 \%$ & 128.57 & 0.265 & $\begin{array}{c}\text { The suspension is white and opaque, and it produces } \\
\text { microprecipitates, which can be dispersed into an } \\
\text { original emulsion. }\end{array}$ \\
\hline Tween + SDS & $0.25 \%+0.25 \%$ & 160.5 & 0.530 & $\begin{array}{l}\text { The suspension is white and opaque, producing } \\
\text { flocculent precipitates and deepening the color of the } \\
\text { system. }\end{array}$ \\
\hline Lecithin + SDS & $0.25 \%+0.25 \%$ & 99.84 & 0.228 & $\begin{array}{c}\text { The suspension is white and opaque, and it produces } \\
\text { microprecipitates, which can be dispersed into an } \\
\text { original emulsion. }\end{array}$ \\
\hline F-68 + PVP K30 & $0.25 \%+0.25 \%$ & 124.2 & 0.247 & $\begin{array}{c}\text { The suspension is white and opaque, and it produces } \\
\text { microprecipitates, which can be dispersed into an } \\
\text { original emulsion. }\end{array}$ \\
\hline
\end{tabular}
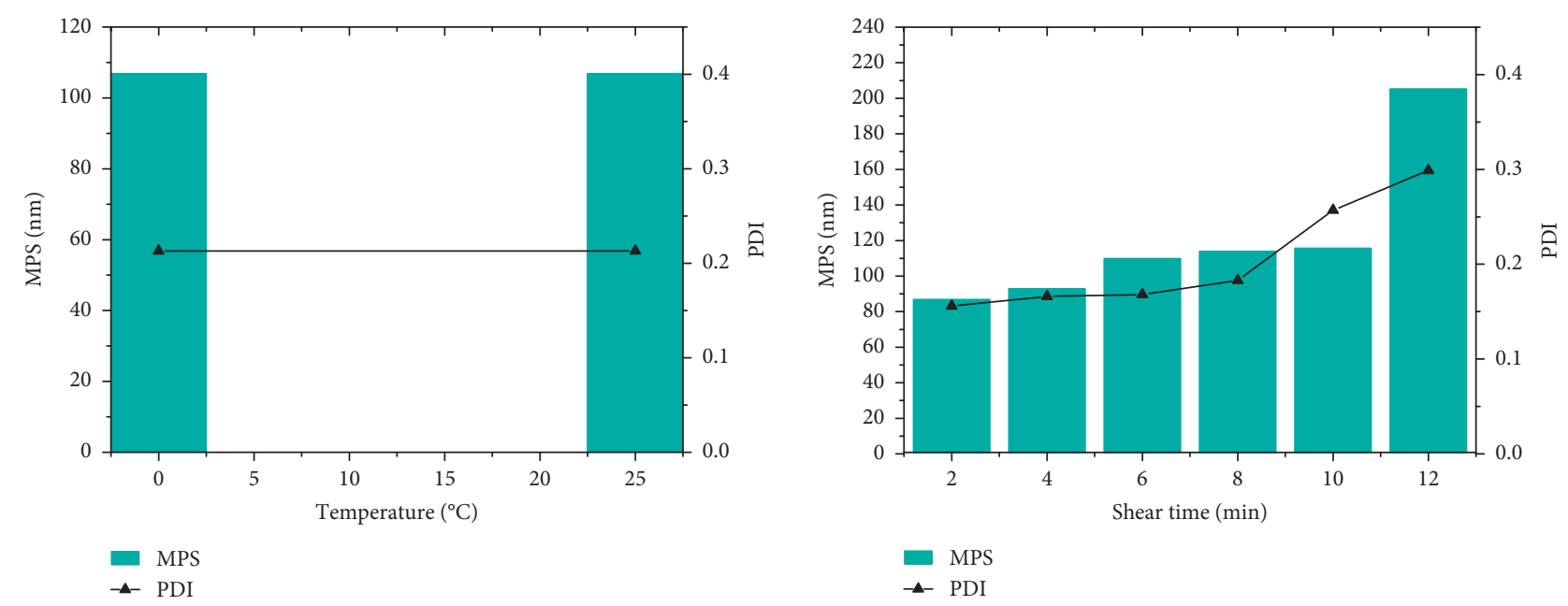

(a)

(b)

FIgURE 3: Continued. 


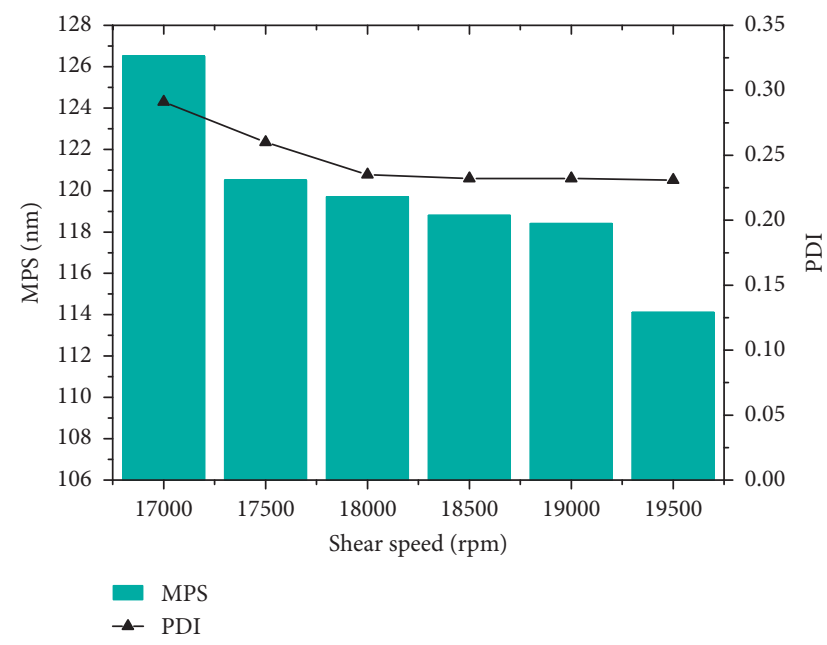

(c)

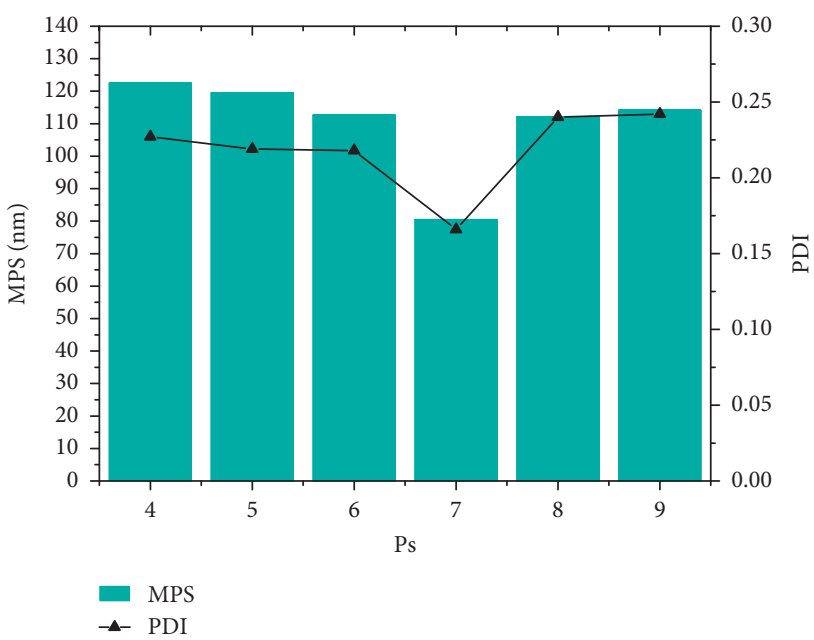

(d)

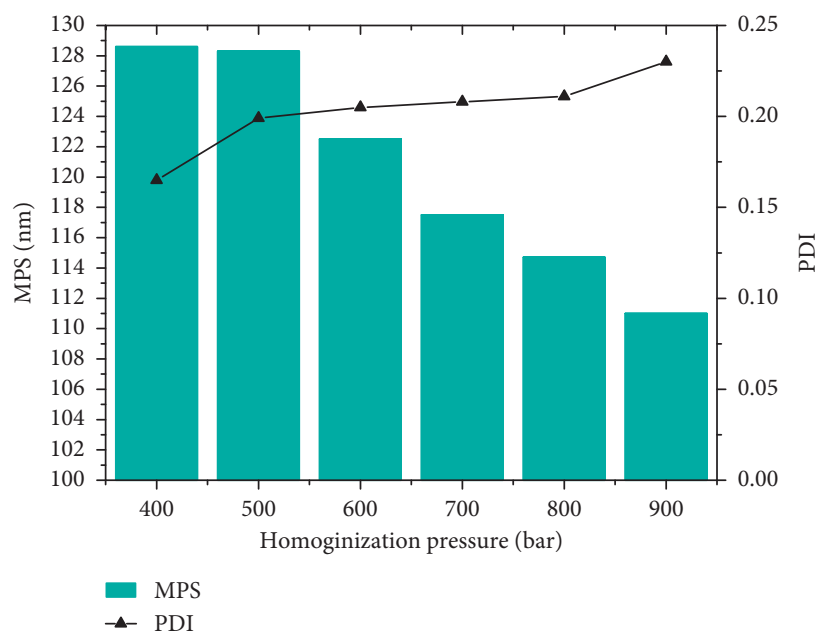

(e)

FiguRE 3: The influences of temperature (a), number of homogenization cycles (b), shear speed (c), shear time (d), and homogenization pressure (e) on the particle size and polydispersity index of Dio-NS preparations.

TABle 5: Variables and levels in the star design.

\begin{tabular}{lcccrr}
\hline Variables & & Levels & +1 & +1.68 \\
\hline Dio (A)\% & -1.68 & -1 & 0 & 0.05 & 0.06 \\
Sph (B)\% & 0.02 & 0.03 & 0.04 & 0.10 & 0.12 \\
SDS (C)\% & 0.03 & 0.05 & 0.08 & 0.10 & 0.12 \\
\hline
\end{tabular}

mixture and dry powder are both in the crystal form of the carrier. The structure did not change, and the crystalline peak of the drug in the Dio-NS freeze-dried powder essentially disappeared, indicating that the drug occurs in an amorphous state and the freeze-drying process has an effect on the crystalline structure of the drug.

3.2.4. In Vitro Dissolution and Stability. As shown in Figure 10, the dissolution rate of dioscin can be significantly improved after the preparation of nanosuspensions. In PBS
( $\mathrm{pH} 7.4$ ), the dissolution rate of Dio-NS during the initial $2 \mathrm{~h}$ was close to $30 \%$, whereas the release rate at $12 \mathrm{~h}$ was close to $90 \%$. The dissolution rate of the physical mixture group was slightly faster than that of the raw material group, which can be attributed to the solubilization effect of the twelve alkyl sulfate and soybean lecithin used in the formulation. However, the dissolution rate was considerably less than that of Dio-NS. It is suggested that the dissolution rate of nanosuspensions is not only caused by the solubilization of excipients but is also mainly due to the reduction of particle size after the formation of nanoscale suspensions. 
TABLE 6: Response value of the formulation using a central composite design $(n=3)$.

\begin{tabular}{|c|c|c|c|c|c|c|}
\hline Run & $A$ & $B$ & $C$ & MPS & PDI & OD \\
\hline 1 & 0 & 0 & 0 & 97.98 & 0.250 & 0.661 \\
\hline 2 & +1 & -1 & +1 & 131.45 & 0.203 & 0.39 \\
\hline 3 & 0 & 0 & 0 & 97.98 & 0.250 & 0.661 \\
\hline 4 & 0 & 0 & 0 & 97.99 & 0.250 & 0.661 \\
\hline 5 & +1 & +1 & +1 & 104.9 & 0.267 & 0.55 \\
\hline 6 & -1 & -1 & -1 & 85.49 & 0.226 & 0.841 \\
\hline 7 & 0 & +1.68 & 0 & 96.9 & 0.25 & 0.67 \\
\hline 8 & -1 & -1 & +1 & 90.29 & 0.235 & 0.772 \\
\hline 9 & -1 & +1 & +1 & 106.4 & 0.27 & 0.53 \\
\hline 10 & +1 & -1 & -1 & 102.4 & 0.261 & 0.59 \\
\hline 11 & 0 & 0 & +1.68 & 98.23 & 0.253 & 0.65 \\
\hline 12 & 0 & 0 & 0 & 97.98 & 0.250 & 0.661 \\
\hline 13 & 0 & 0 & 0 & 97.98 & 0.250 & 0.661 \\
\hline 14 & +1.68 & 0 & 0 & 141.6 & 0.345 & 0 \\
\hline 15 & +1 & +1 & -1 & 92.93 & 0.24 & 0.74 \\
\hline 16 & -1.68 & 0 & 0 & 108.24 & 0.274 & 0.5 \\
\hline 17 & 0 & -1.68 & 0 & 91.56 & 0.239 & 0.75 \\
\hline 18 & 0 & 0 & 0 & 98.97 & 0.250 & 0.661 \\
\hline 19 & 0 & 0 & -1.68 & 74.88 & 0.238 & 0.868 \\
\hline 20 & -1 & +1 & -1 & 101.57 & 0.263 & 0.59 \\
\hline
\end{tabular}

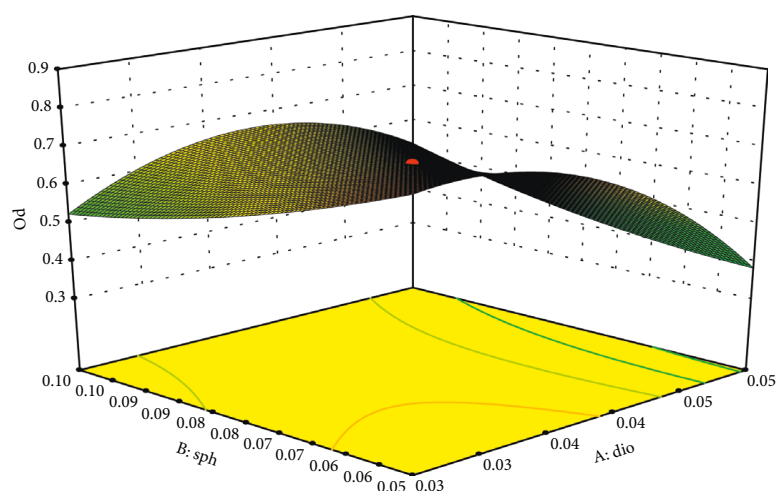

(a)

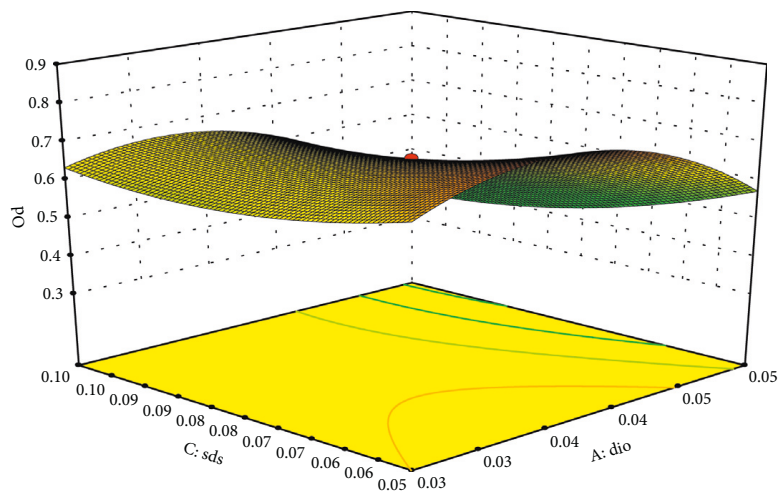

(c)

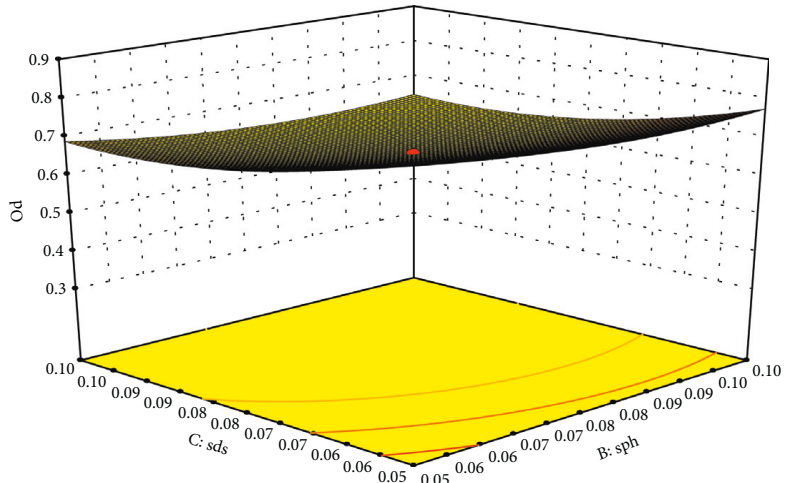

(b)

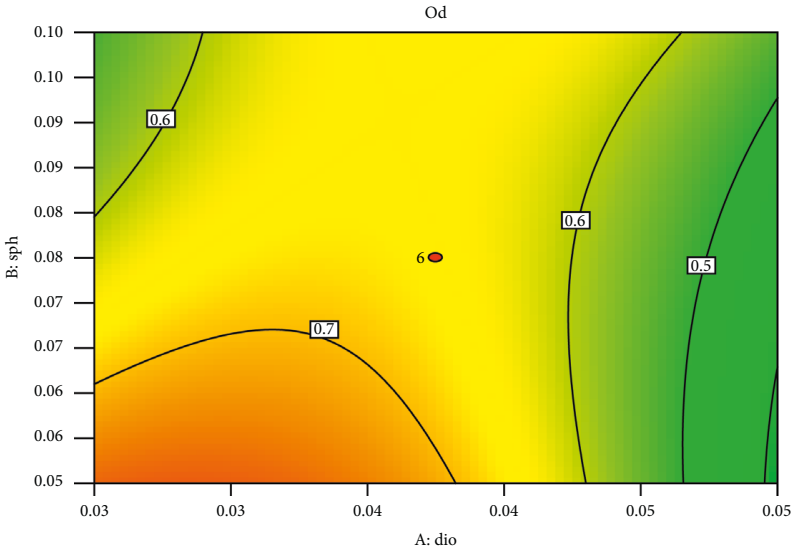

(d)

Figure 4: Continued. 


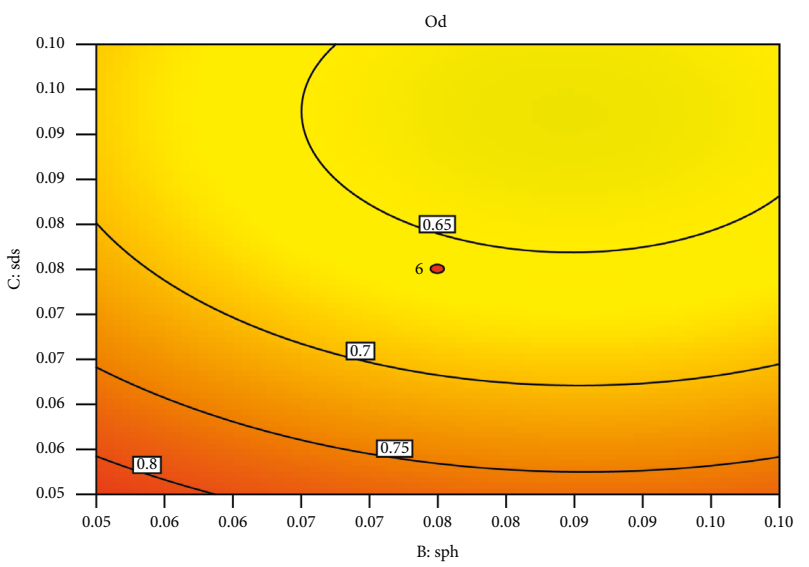

(e)

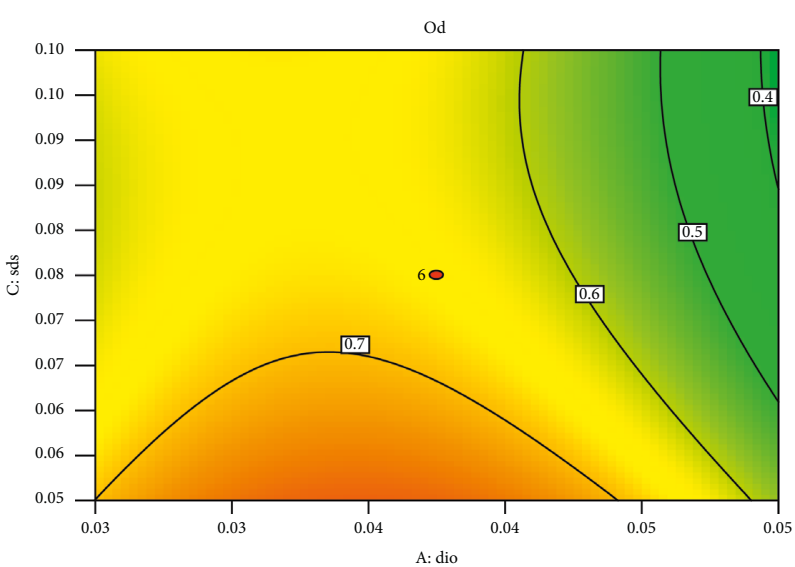

(f)

FIGURE 4: The response surface model of the reciprocal action among the concentrations of dioscin\% (A), soybean lecithin (B), and SDS (C) on OD.

Table 7: Particle size and zeta potential of the optimum Dio-NS $(n=3, x \pm s)$.

\begin{tabular}{lccr}
\hline Batch no. & Particle size $(\mathrm{nm})$ & PDI & ZP $(\mathrm{mV})$ \\
\hline VAL1001 & $106.5 \pm 0.50$ & $0.177 \pm 0.02$ & $-32.13 \pm 2.35$ \\
VAL1002 & $115.73 \pm 0.76$ & $0.231 \pm 0.002$ & $-33.1 \pm 5.26$ \\
VAL1003 & $97.93 \pm 1.26$ & $0.254 \pm 0.02$ & $-37.6 \pm 2.53$ \\
Mean value & $106.72 \pm 8.90$ & $0.221 \pm 0.04$ & $-34.27 \pm 2.91$ \\
\hline
\end{tabular}

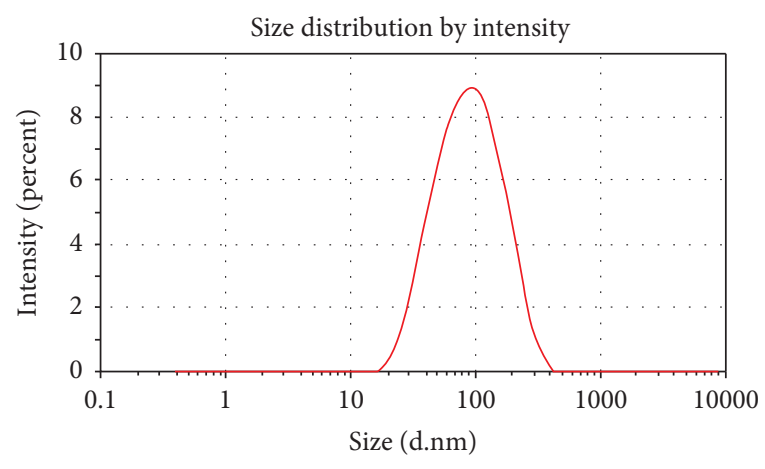

(a)

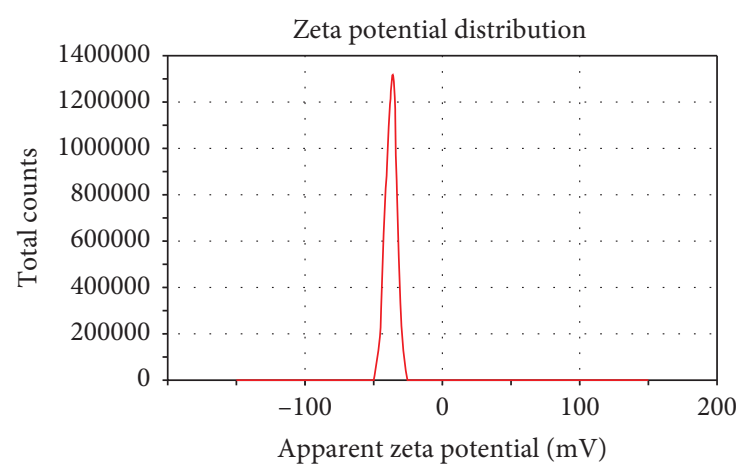

(b)

FIGURE 5: Particle size and zeta potential distribution of Dio-NS formulations.

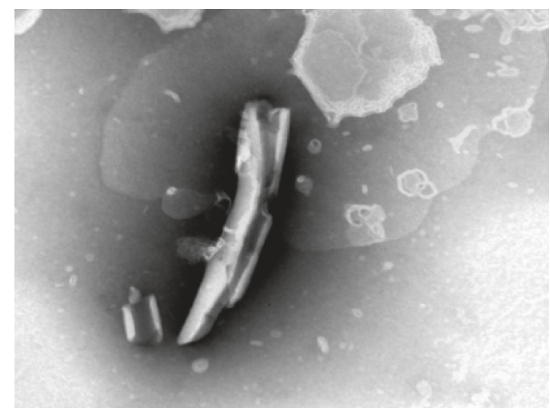

(a)

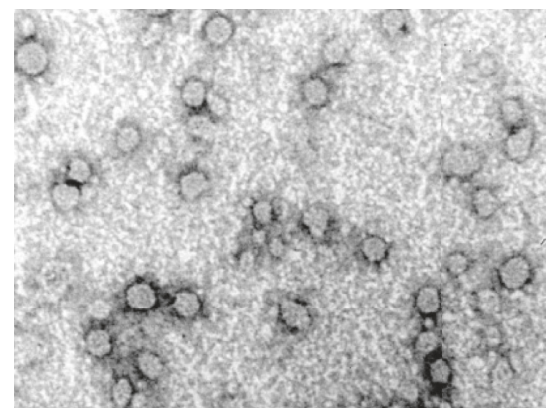

(b)

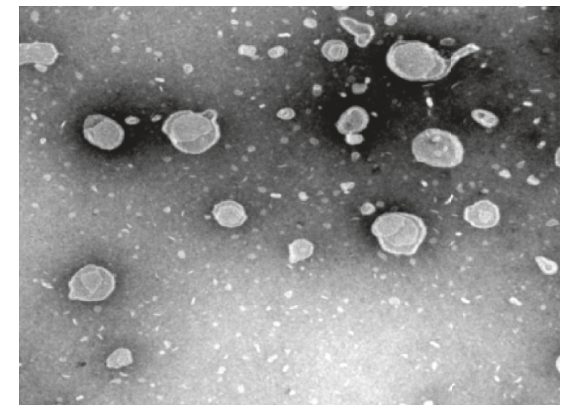

(c)

Figure 6: Transmission electron micrographs of samples dispersed in water. (a) Dioscin. (b) Dio-NS. (c) Dio-NS powder. 


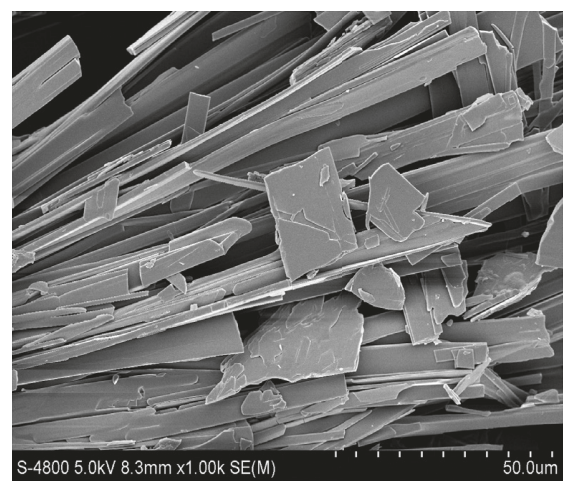

(a)

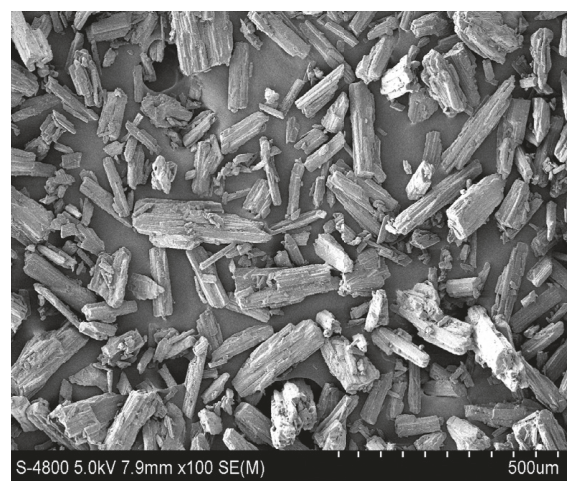

(b)

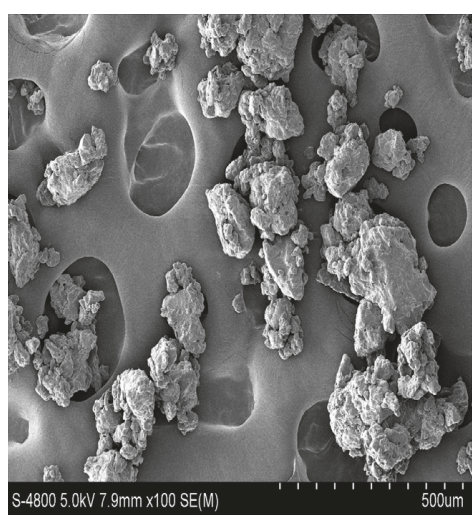

(c)

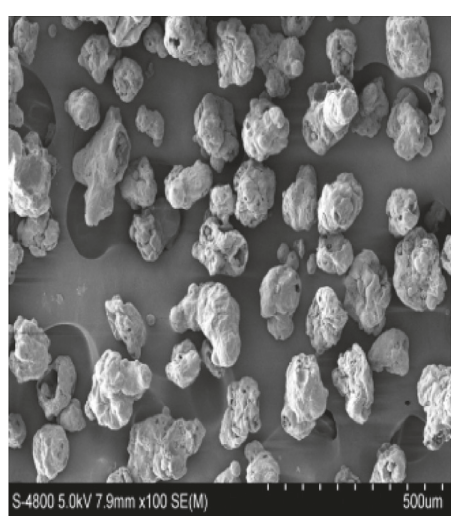

(d)

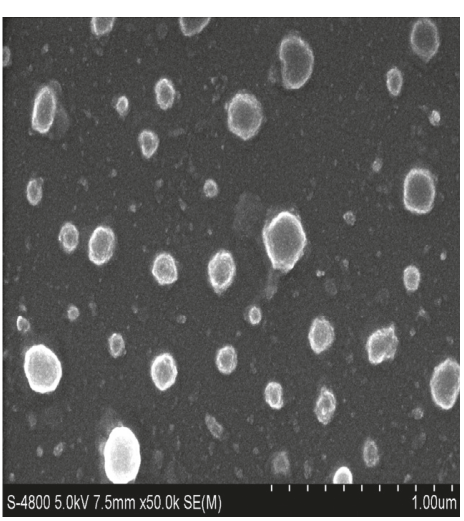

(e)

FIgURE 7: Scanning electron micrographs of (a) dioscin raw material, (b) with mannitol, (c) with soybean lecithin, (d) with twelve alkyl sulfates, and (e) Dio-NS lyophilized powder.

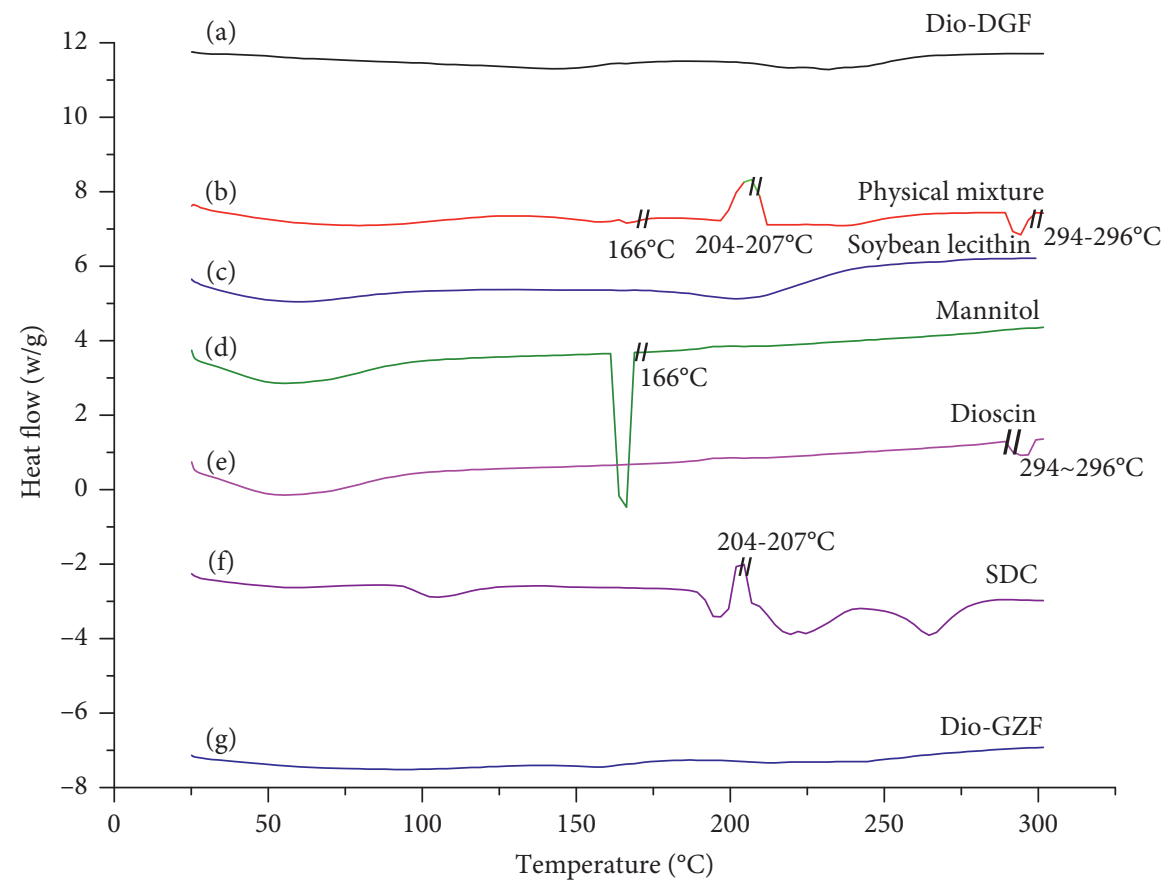

FiguRE 8: DSC patterns of freeze-dried Dio-NS (a), physical mixture (b), soybean lecithin (c), mannitol (d), raw dioscin (e), SDS (f), and dry Dio-NS (g). 


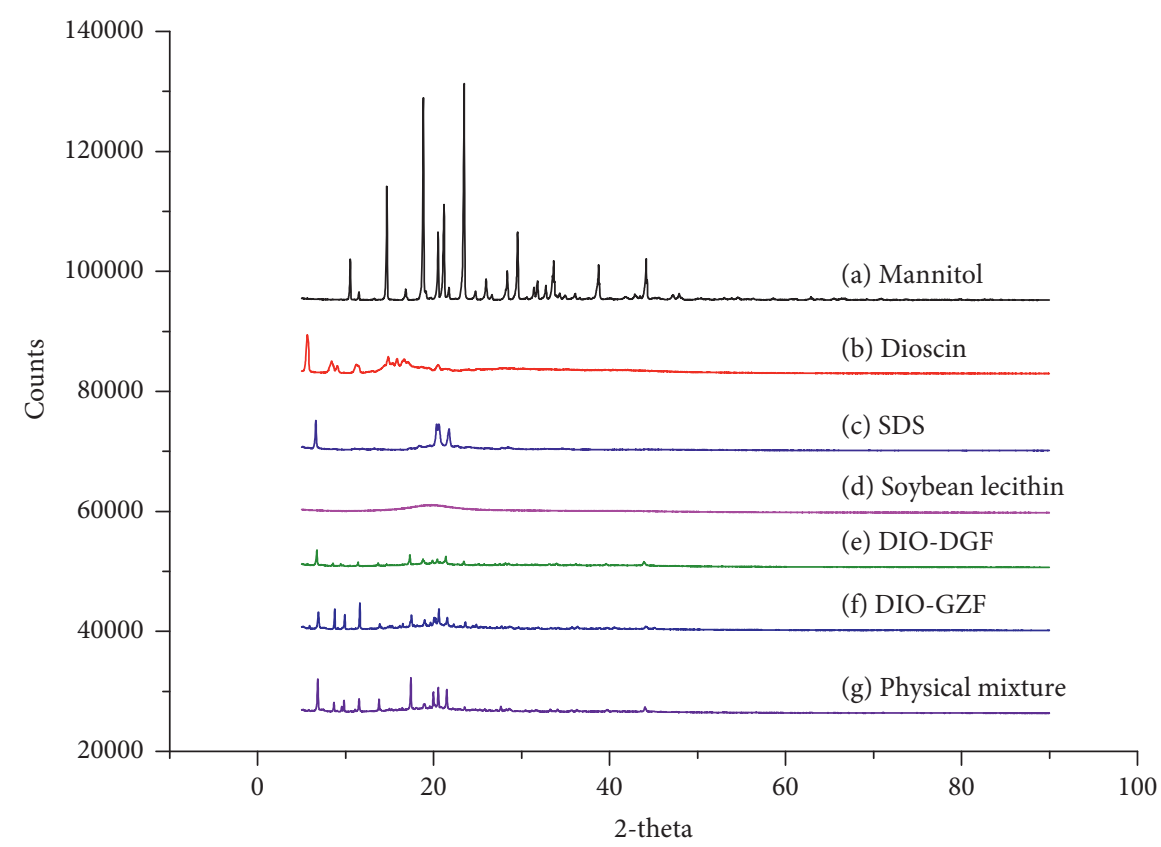

FIGURE 9: X-ray diffraction patterns of mannitol (a), raw dioscin (b), SDS (c), soybean lecithin (d), freeze-dried Dio-NS (e), dry Dio-NS (f), and physical mixture (g).

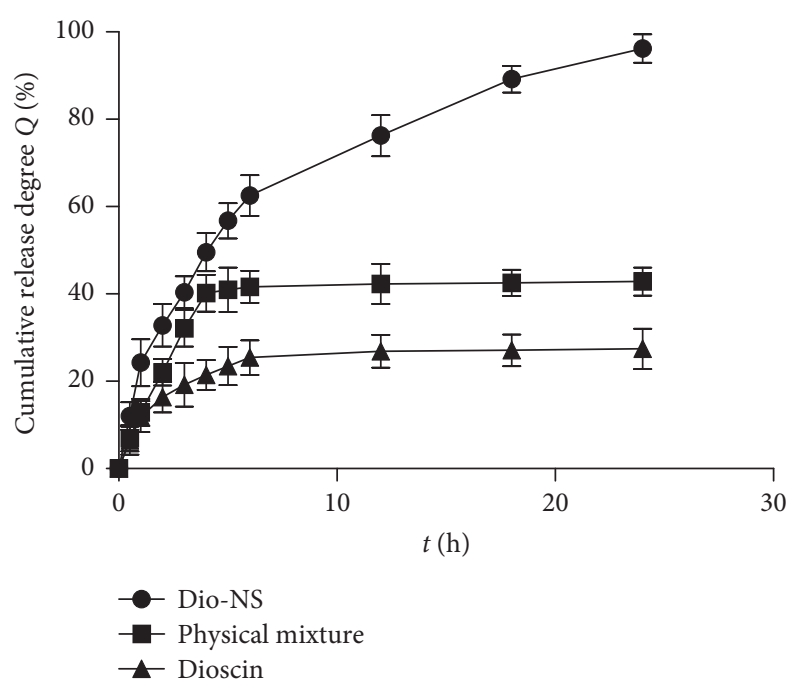

FIGURE 10: In vitro dissolution of dioscin nanosuspensions.

The results showed that although the non freeze-dried Dio-NS had poor stability at room temperature (Figures 11 and 12), the freeze-dried powder remained stable for 2 months (Table 3 ).

\subsection{The Effects of Dio-NS on Liver Preservation}

3.3.1. Serum Biochemistry and Hepatic Lipid Peroxidation Assays. In order to assess the influence of Dio-NS on $\mathrm{CCl}_{4}$ induced liver damage, the activities of ALT, AST, TNF- $\alpha$, IL$1 \beta$, and IL-6 in the serum were monitored (Figure 13). The results indicate that our model is successful, given that the model groups show significant difference compared with the control $(p<0.01)$. Compared with the model groups, there were significant differences in groups with different Dio-NS and silymarin doses $(p<0.01$ and $p<0.05)$.

The results of our analysis of liver lipid peroxidation showed that the activity of GSH-Px and SOD in different dose groups of Dio-NS were markedly increased, compared with those of the model control $(p<0.01$ and $p<0.05)$ (Figure 13). In contrast, the level of MDA was significantly reduced $(p<0.01$ and $p<0.05)$. In the different drug groups, the liver index was reduced to some extent. Consequently, 


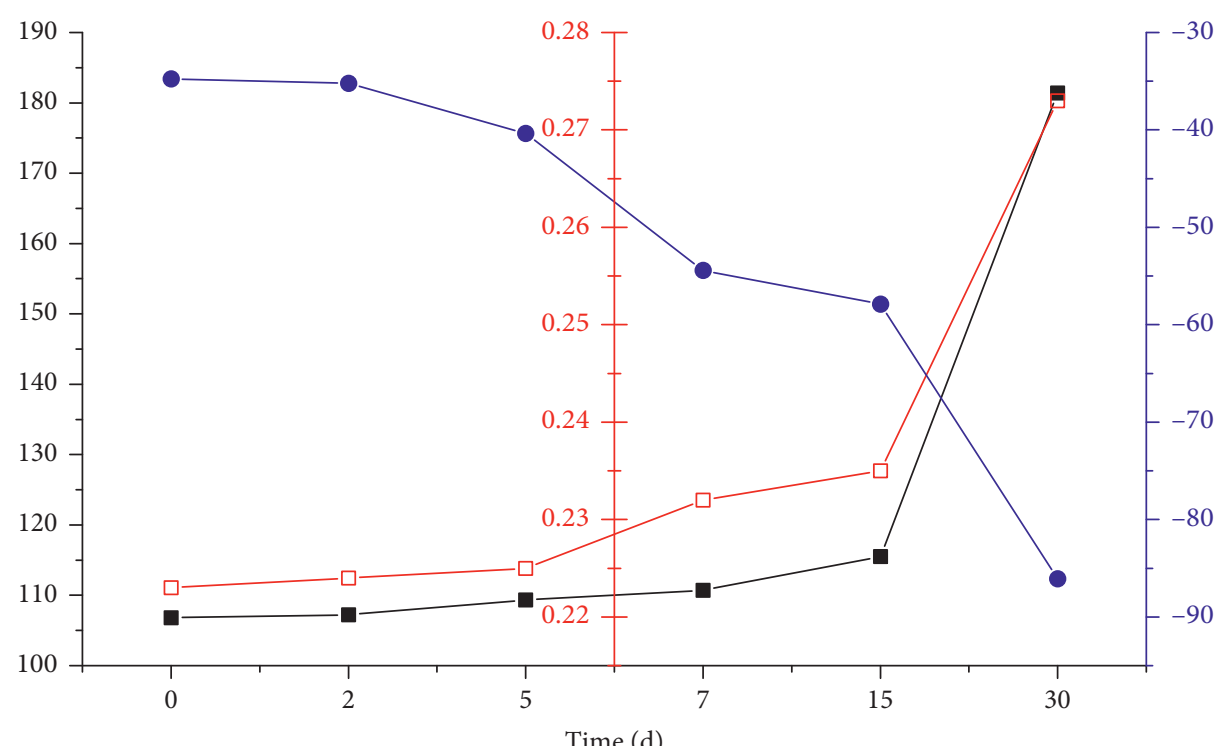

- - Size (nm)

$-\square-$ PDI

-๑- Zeta

Figure 11: Particle size, polydispersity index, and zeta potential of dioscin nanoscale suspension NS-B at $25^{\circ} \mathrm{C}$.

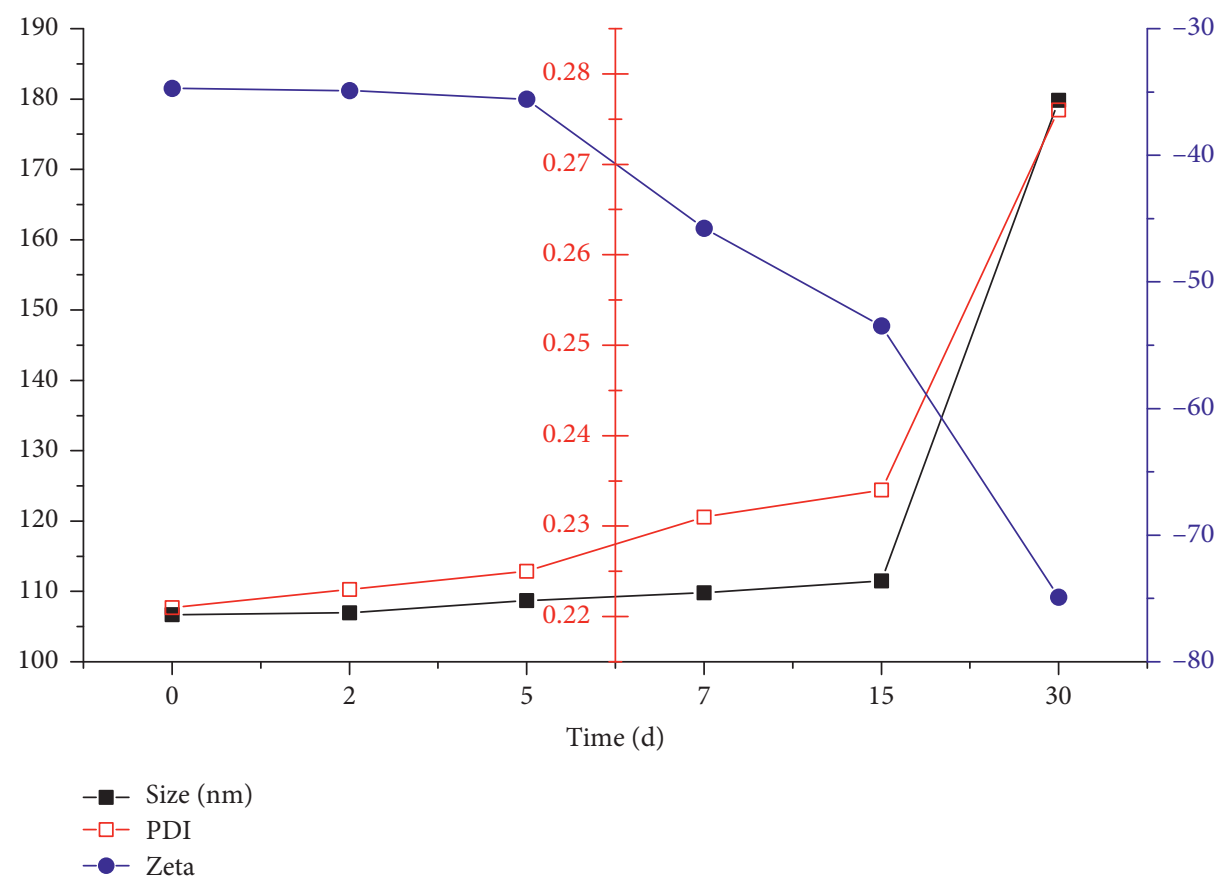

Figure 12: Particle size, polydispersity index, and zeta potential of dioscin nanoscale suspension NS-B at $4^{\circ} \mathrm{C}$.

there was an equivalent or even better effect from the highdose group $(100 \mathrm{mg} / \mathrm{kg})$ of Dio-NS compared with that of silymarin (the positive control drug).

HE staining showed that the liver cells in the blank control group were arranged normally, the cytoplasm was uniform, the nucleus and nucleolus were obvious, the central vein was clearly visible, and the cells had local edema (Figure 14). In the model group, a large number of necrotic hepatocytes were observed in the tissue, as indicated by a more intense staining or disintegration of liver cells. Furthermore, cytoplasmic eosinophilia was enhanced, accompanied by infiltration of inflammatory cells, and a small amount of white blood cells were seen in the veins. In the silymarin group and the high-dose group 


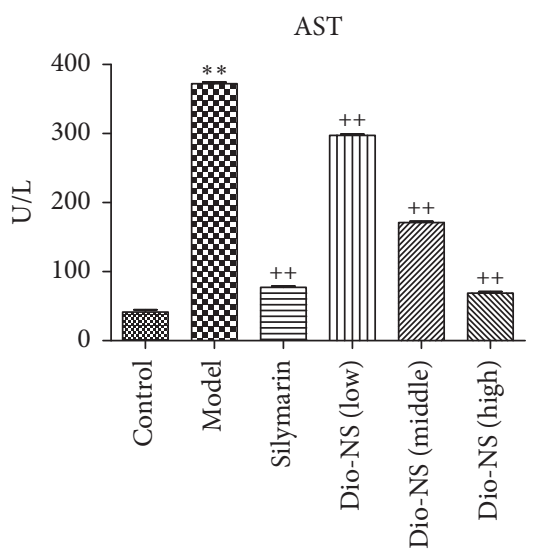

(a)

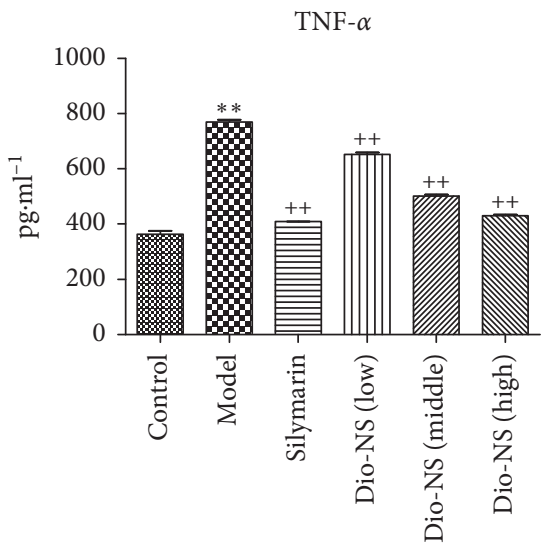

(d)

MDA

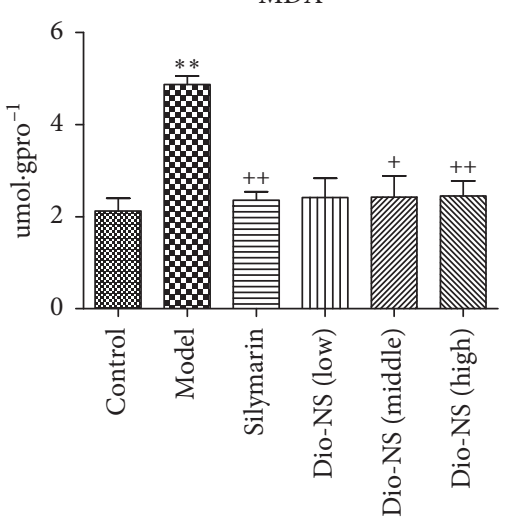

(g)

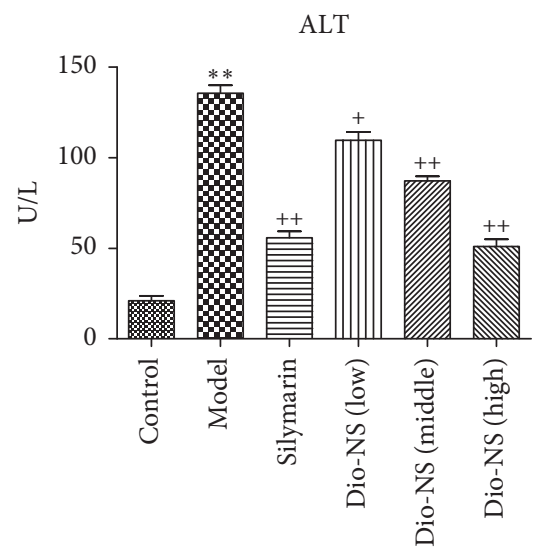

(b)

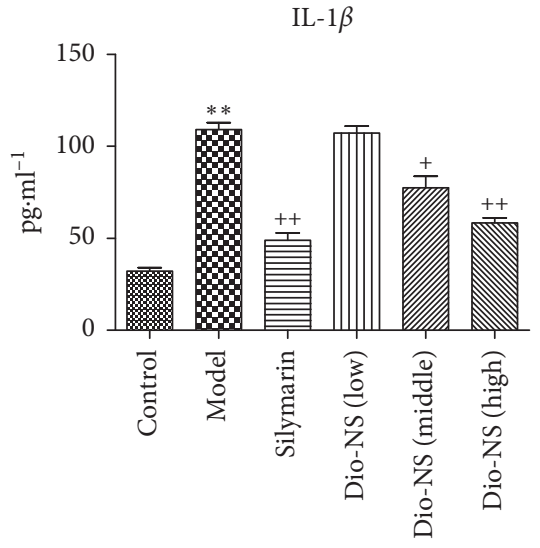

(e)

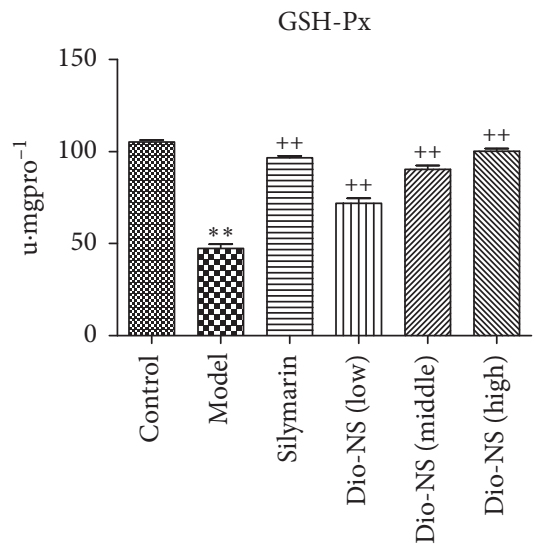

(h)

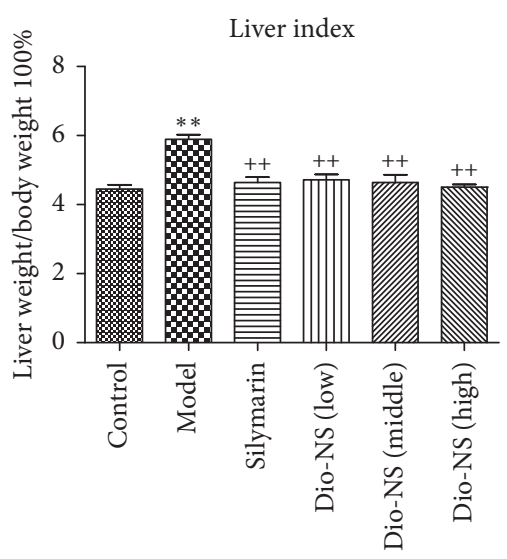

(c)

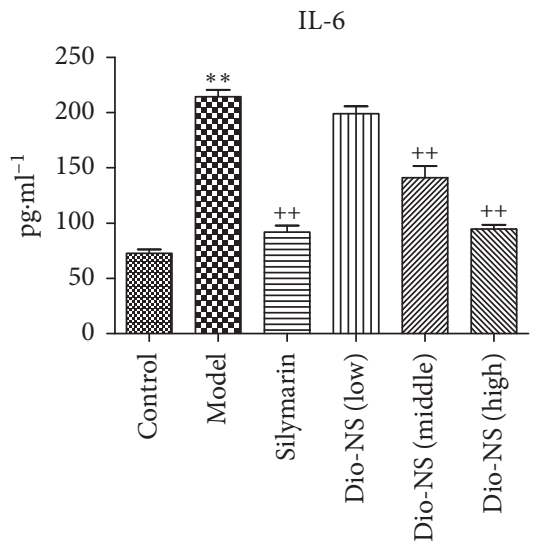

(f)

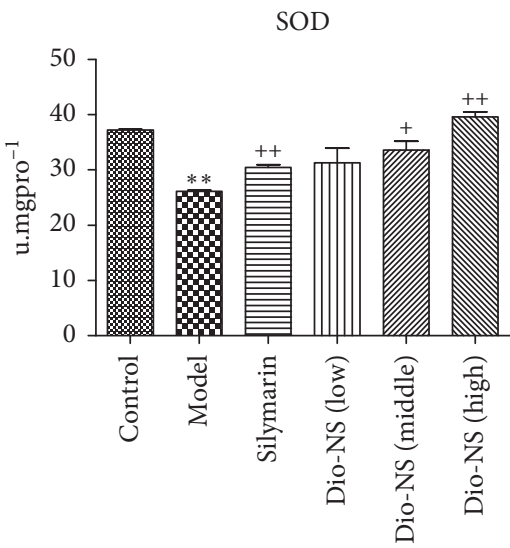

(i)

FIgURE 13: Effect of Dio-NS on CCl4-induced hepatotoxicity. (a) The activities of ALTin the serum. (b) The activities of ASTin the serum. (c) The liver index. (d) The activities of TNF-a in the serum. (e) The activities of IL-1 $\beta$ in the serum. (f ) The activities of IL- 6 in the serum. (g) The levels of MDA in the liver. (h) The levels of GSH-px in the liver. (i) The levels of SOD in the liver. ${ }^{* *} P<0.01 \mathrm{vs}$ control, $+P<0.05$, and $++P<0.01$ vs. model.

of Dio-NS, the structure of hepatocyte was more complete with few inflammatory cells and little necrosis, and the pathological damage was clearly ameliorated. Compared with the model group, the low- and medium-dose groups of Dio-NS decreased the infiltration of inflammatory cells and reduced the degree of hepatocyte damage to a certain extent; however, the effect was not as conspicuous as in the silymarin and high-dose Dio-NS groups.

\section{Discussion}

It is well known that nanoparticle formulations improve the solubility of drugs to some extent because of their small size. However, in the process of drug preparation, excessive heat and solvent residues can adversely affect the production of good formulations. However, dioscin dissolves in ethanol, which has beneficial effects with regards to our preparation, 


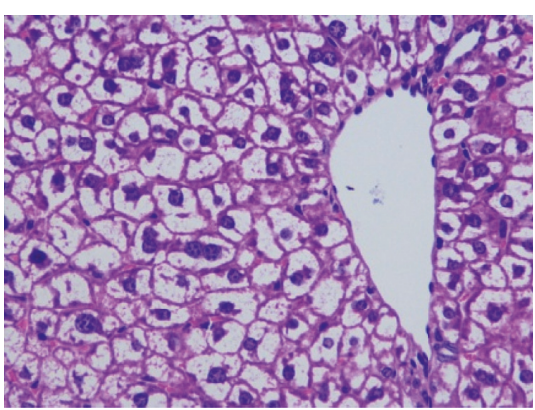

(a)

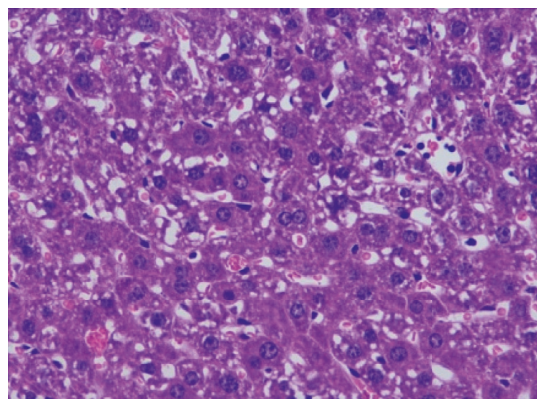

(d)

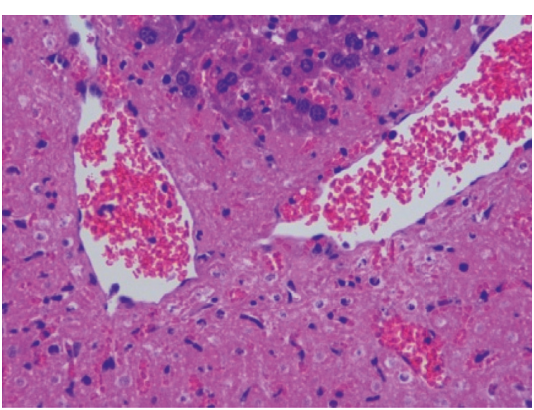

(b)

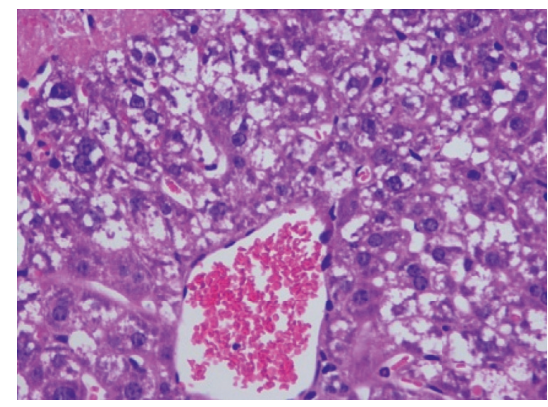

(e)

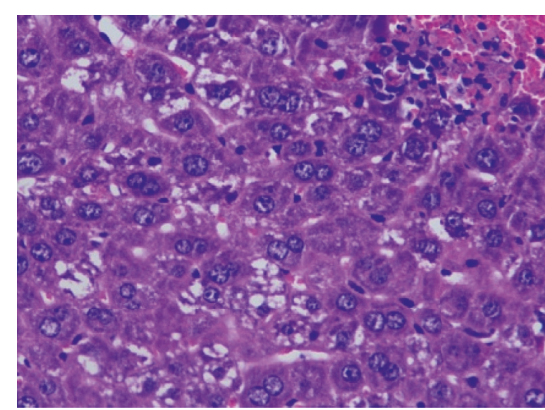

(c)

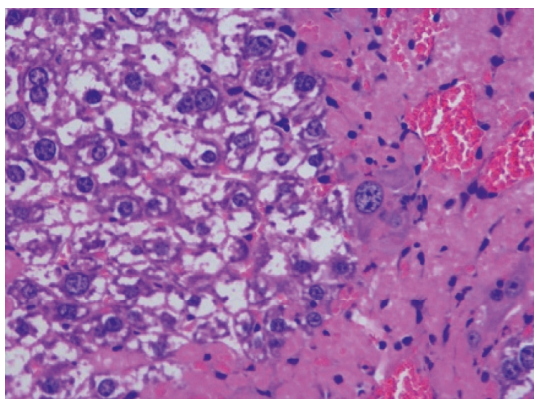

(f)

FIGURe 14: HE staining of liver cells: (a) control, (b) model, (c) silymarin, (d) Dio-NS (high), (e) Dio-NS (medium), and (f) Dio-NS (low).

as the rapid volatility of ethanol ensures low amounts of solvent residue.

In previous experiments, we used the reverse solvent preparation method and this method combined with highpressure homogenization to prepare nanoemulsions. However, when using high-pressure homogenization, we found that the heat generated caused the production of excessive amounts of foam, which we believe may be attributable to the thermal decomposition of surfactants or dioscin. Moreover, using the reverse solvent preparation method alone, we were not able to obtain particles of the requisite size. Therefore, in the present study, we examined the applicability of using magnetic stirring and high-speed shearing combined with high-pressure homogenization to prepare the Dio-NS. Using this approach, the excessive heat generated by homogenization can be dissipated, thereby minimizing or eliminating foaming or degradation of the drug preparation.

Furthermore, we adopted a star design-response surface optimization method in order to determine the optimal formulation ratio. This enabled us to clearly assess each level of interaction. We were surprised to discover that the ratio of dioscin in the formulation was as high as $21.26 \%$.

Through an evaluation of the physical and chemical properties and morphology of Dio-NS, we discovered that the nature of dioscin in the formulation had undergone changes. Observations indicated that the dioscin no longer retained a crystalline form, but instead occurred as spherical particles, as indicated by the disappearance of peaks on thermal analysis.

On the basis of an in vitro solubility test, we found that the solubility of dioscin was significantly increased in the
Dio-NS formulations. This was confirmed by pharmacodynamic experiments. The possible reasons for these observed properties are as follows. Firstly, the particle size decreases, the adsorption surface is enlarged, the saturation solubility increases, the dissolution rate increases, the permeability of the biofilm increases, at the same time the retention time of the gastrointestinal tract is prolonged, the concentration of drug in the blood is enhanced, and thus the efficacy of the drug is enhanced. Secondly, when drug particles are less than $1 \mu \mathrm{m}$ in size, the internal dissolution rate will suddenly increase.

However, we did not evaluate the bioavailability of DioNS. In this study, we examined the use of ultrahigh liquid phase and liquid mass in combination but were unable to detect any dioscin. On the one hand, dioscin exists in the body in the form of glycogen. On the other hand, there were impertinent methods on handling samples or the type of instruments. These problems will be difficult to solve in subsequent experiments.

\section{Conclusion}

We have demonstrated that nanosuspensions can be successfully prepared using an emulsification method in which high-speed homogenization is used in combination with high-pressure homogenization, which is better than previously prepared drug formulations $[32,33]$. Dioscin is an effective component extracted from plants that belong to the family Dioscoreaceae. The present study shows that dioscin has protective effect against acute hepatic injury in mice induced by intraperitoneal injection of $\mathrm{CCL}_{4}$. However, dioscin is difficult to dissolve in water, although it can be dissolved in the organic solvent ethanol [34]. Therefore, in 
this study, we adopted the methods of reverse solvent precipitation and high-pressure homogenization [35] to prepare nanosuspensions. The particle size distribution of the resulting suspensions is between 70 and $120 \mathrm{~nm}$. The suspensions also have a high specific surface area and increased solubility, which may promote their bioavailability.

Therefore, we performed various pharmacodynamic analyses to evaluate the bioavailability of our newly prepared nanosuspensions (Dio-NS). We accordingly found that, at a high dose, Dio-NS reduces the levels of ALT and AST, enhances SOD activity, reduces MDA content, and ameliorates liver pathology to some extent compared with silymarin (the positive control drug).

Thus, the results of the present study will provide a reference for the development and clinical application of dioscin formulations. Finally, in further studies, we intend to evaluate the bioavailability of our dioscin formulations and investigate the precise mechanisms underlying the hepatoprotection properties of these preparations.

$\begin{array}{ll}\text { Abbreviations } \\ \text { Dio: } & \text { Dioscin } \\ \text { DSC: } & \text { Differential scanning calorimetry } \\ \text { Dio-NS: } & \text { Dioscin nanosuspension } \\ \text { E t: } & \text { Emulsification time } \\ \text { HP: } & \text { Homogenization pressure } \\ \text { HPH: } & \text { High-pressure homogenization } \\ \text { HPLC: } & \text { High-performance liquid chromatography } \\ \text { MPS: } & \text { Mean particle size } \\ \text { OD: } & \text { Overall desirability } \\ \text { PSD: } & \text { Particle size distribution } \\ \text { P s: } & \text { Passes } \\ \text { SEM: } & \text { Scanning electron microscope } \\ \text { SDS: } & \text { Sodium alkyl sulfate twelve } \\ \text { Tem: } & \text { Transmission electron microscope } \\ \text { XRPD: } & \text { X-ray powder diffraction } \\ \text { ZP: } & \text { Zeta potential. }\end{array}$

\section{Data Availability}

All relevant data are within the paper and its Supporting Information files.

\section{Conflicts of Interest}

There are no conflicts of interest.

\section{Authors' Contributions}

Xiao Song and Hongye Ju contributed equally to this work. Xiao Song conceived and designed the experiments. Hongye Ju, Kunxia Hu, Li-Zhu Han, and GuoWang Zhao performed the experiments. The rest of the authors were also involved in the different processes of the experiments. Xiao Song, Hongye Ju, Guo-Wang Zhao analyzed the data and wrote the paper. Xiao Song and Zhi-Shu Tang provided funding for scientific research.

\section{Acknowledgments}

The authors would like to acknowledge the financial support from the National Natural Science Foundation of China (nos. 81373944 and 81373978), the Department of Science and Technology of Shaanxi Province (2012KTCQ03-13), the Key Laboratory of the Basic and New Medicine Research of the Traditional Chinese Medicine in Shaanxi Province, the Special Subsidization of the Key Subjects of the Traditional Chinese Medicine Pharmacy in Shaanxi Province, and the Three Level Laboratory of the Chinese Medicine Preparation of the State Administration of Traditional Chinese Medicine (TCM).

\section{Supplementary Materials}

Supplementary Table S1-3: three experimental data during the preparation of nanosuspensions, which describe the effects of shear speed, shear time, temperature, homogenization times, and homogenization pressure on the particle size and polydispersity index of nanosuspensions, and the evaluation results in vitro and in vivo. The experimental results were plotted by origin 8.5 and GraphPad Prism 5. Supplementary Material 1: Animal Ethics Society approval document. (Supplementary Materials)

\section{References}

[1] C. Zhu, N. Bao, S. Chen, and J. Zhao, "Dioscin enhances osteoblastic cell differentiation and proliferation by inhibiting cell autophagy via the ASPP2/NF- $\alpha \beta$ pathway," Molecular Medicine Reports, vol. 16, no. 4, pp. 4922-4926, 2017.

[2] H. Zeng, L. Yang, X. Zhang, Y. Chen, and J. Cai, "Dioscin prevents LPS-induced acute lung injury through inhibiting the TLR4/MyD88 signaling pathway via upregulation of HSP70," Molecular Medicine Reports, vol. 17, no. 5, pp. 6752-6758, 2018.

[3] Y. S. Zhang, Y. L. Ma, K. Thakur et al., "Molecular mechanism and inhibitory targets of dioscin in HepG2 cells," Food and Chemical Toxicology, vol. 120, pp. 143-154, 2018.

[4] S. Zhu, S. Tang, and F. Su, "Dioscin inhibits ischemic stroke induced inflammation through inhibition of the TLR4/ MyD88/NFkB signaling pathway in a rat model," Molecular Medicine Reports, vol. 17, no. 1, pp. 660-666, 2018.

[5] L. Zheng, L. Yin, L. Xu et al., "Protective effect of dioscin against thioacetamide-induced acute liver injury via FXR/ AMPK signaling pathway in vivo," Biomedicine \& Pharmacotherapy, vol. 97, pp. 481-488, 2018.

[6] C. Li, Y. Lu, S. Du et al., "Dioscin exerts protective effects against crystalline silica-induced pulmonary fibrosis in mice," Theranostics, vol. 7, no. 17, pp. 4255-4275, 2017.

[7] L. Yin, Y. Qi, Y. Xu et al., "Dioscin inhibits HSC-T6 cell migration via adjusting SDC-4 expression: insights from iTRAQ-based quantitative proteomics," Frontiers in Pharmacology, vol. 8, p. 665, 2017.

[8] X. Tao, L. Yin, L. Xu, and J. Peng, "Dioscin: a diverse acting natural compound with therapeutic potential in metabolic diseases, cancer, inflammation and infections," Pharmacological Research, vol. 137, pp. 259-269, 2018.

[9] Y. Qin, X. Wu, W. Huang et al., "Acute toxicity and subchronic toxicity of steroidal saponins from Dioscorea 
zingiberensis C.H.Wright in rodents," Journal of Ethnopharmacology, vol. 126, no. 3, pp. 543-550, 2009.

[10] X. J. Liang, Y. Z. Shang, H. R. Song, and W. J. Dong, “Acute toxicity study of whole saponin of Dioscorea nipponica Makino in mice," Journal of Chengde Medical College, vol. 27, pp. 117-118, 2010.

[11] T. Xu, S. Zhang, L. Zheng, L. Yin, L. Xu, and J. Peng, "A 90-day subchronic toxicological assessment of dioscin, a natural steroid saponin, in Sprague-Dawley rats," Food and Chemical Toxicology, vol. 50, no. 5, pp. 1279-1287, 2012.

[12] L. Padrela, M. A. Rodrigues, A. Duarte, A. M. A. Dias, M. E. M. Braga, and H. C. de Sousa, "Supercritical carbon dioxide-based technologies for the production of drug nanoparticles/nanocrystals-a comprehensive review," Advanced Drug Delivery Reviews, vol. 131, pp. 22-78, 2018.

[13] L. R. Zawar and S. B. Bari, "Preparation, characterization and in vivo assessment of repaglinide nanosuspension for oral bioavailability improvement," Recent Patents on Drug Delivery and Formulation, vol. 12, no. 3, pp. 162-169, 2018.

[14] A. G. Thombre, J. C. Shah, K. Sagawa, and W. B. Caldwell, "In vitro and in vivo characterization of amorphous, nanocrystalline, and crystalline ziprasidone formulations," International Journal of Pharmaceutics, vol. 428, no. 1-2, pp. 8-17, 2012.

[15] M. H. He, L. Chen, T. Zheng et al., "Potential applications of nanotechnology in urological cancer," Frontiers in Pharmacology, vol. 9, p. 745, 2018.

[16] N. Kamaly, J. C. He, D. A. Ausiello, and O. C. Farokhzad, "Nanomedicines for renal disease: current status and future applications," Nature Reviews Nephrology, vol. 12, no. 12, pp. 738-753, 2016.

[17] D. C. Snow-Lisy, M. K. Samplaski, V. Labhasetwar, and E. S. Sabanegh Jr, "Drug delivery to the testis: current status and potential pathways for the development of novel therapeutics," Drug Delivery and Translational Research, vol. 1, no. 5, pp. 351-360, 2011.

[18] P. J. Patel, B. Y. Gajera, and R. H. Dave, “A quality-by-design study to develop Nifedipine nanosuspension: examining the relative impact of formulation variables, wet media milling process parameters, and excipient variability on drug product quality attributes," Drug Development and Industrial Pharmacy, vol. 44, no. 12, pp. 1942-1925, 2018.

[19] A. N. Oktay, A. Karakucuk, S. Ilbasmis-Tamer, and N. Celebi, "Dermal flurbiprofen nanosuspensions: optimization with design of experiment approach and in vitro evaluation," European Journal of Pharmaceutical Sciences, vol. 15, no. 122, pp. 254-263, 2018.

[20] E. B. Basalious and M. A. Ahmed, "Phospholipid based selfnanoemulsifying self-nanosuspension (p-SNESNS) as a dual solubilization approach for development of formulation with diminished food effect: fast/fed in vivo pharmacokinetics study in human," European Journal of Pharmaceutical Sciences, vol. 109, pp. 244-252, 2017.

[21] H. Liu, Z. Zhang, H. Hu et al., "Protective effects of Liuweiwuling tablets on carbon tetrachloride-induced hepatic fibrosis in rats," BMC Complementary and Alternative Medicine, vol. 18, no. 1, p. 212, 2018.

[22] X. Jiang, H. Zhang, K. Mehmood et al., "Protective effects of Herpetospermum caudigerum extracts against liver injury induced by carbon tetrachloride in mouse," Journal of Biological Regulators \& Homeostatic Agents, vol. 32, no. 3, pp. 699-704, 2018.

[23] J. Leng, Z. Wang, C.-L. Fu et al., "NF-kappaB and AMPK/ $\mathrm{PI} 3 \mathrm{~K} / \mathrm{Akt}$ signaling pathways are involved in the protective effects of Platycodon grandiflorum saponins against acetaminophen-induced acute hepatotoxicity in mice," Phytotherapy Research, vol. 32, no. 11, pp. 2235-2246, 2018.

[24] C. Ning, X. Gao, C. Wang et al., "Ginsenoside Rg1 protects against acetaminophen-induced liver injury via activating Nrf2 signaling pathway in vivo and in vitro," Regulatory Toxicology and Pharmacology, vol. 98, pp. 58-68, 2018.

[25] H. Zhao, Q. Han, N. Lu, D. Xu, Z. Tian, and J. Zhang, "HMBOX1 in hepatocytes attenuates LPS/D-GalN-induced liver injury by inhibiting macrophage infiltration and activation," Molecular Immunology, vol. 101, pp. 303-311, 2018.

[26] H. Lv, X. Fan, L. Wang, H. Feng, and X. Ci, "Daphnetin alleviates lipopolysaccharide/d-galactosamine-induced acute liver failure via the inhibition of NLRP3, MAPK and NF- $\kappa B$, and the induction of autophagy," International Journal of Biological Macromolecules, vol. 119, pp. 240-248, 2018.

[27] P. Kanmani and H. Kim, "Protective effects of lactic acid bacteria against TLR4 induced inflammatory response in hepatoma HepG2 cells through modulation of toll-like receptor negative regulators of mitogen-activated protein kinase and NF- $\mathrm{kB}$ signaling," Frontiers in Immunology, vol. 9, p. 1537, 2018.

[28] B. Lu, Y. Xu, L. Xu et al., "Mechanism investigation of dioscin against $\mathrm{CCl}_{4}$-induced acute liver damage in mice," Environmental Toxicology and Pharmacology, vol. 34, no. 2, pp. 127-135, 2012.

[29] Y.-J. Son, P. W. Longest, G. Tian, and M. Hindle, "Evaluation and modification of commercial dry powder inhalers for the aerosolization of a submicrometer excipient enhanced growth (EEG) formulation," European Journal of Pharmaceutical Sciences, vol. 49, no. 3, pp. 390-399, 2013.

[30] G. Pilcer, T. Sebti, and K. Amighi, "Formulation and characterization of lipid-coated tobramycin particles for dry powder inhalation," Pharmaceutical Research, vol. 23, no. 5, pp. 931-940, 2006.

[31] W. Yang, J. Tam, D. A. Miller et al., "High bioavailability from nebulized itraconazole nanoparticle dispersions with biocompatible stabilizers," International Journal of Pharmaceutics, vol. 361, no. 1-2, pp. 177-188, 2008.

[32] Y. Li, X. Zhao, Y. Zu, and Y. Zhang, "Preparation and characterization of paclitaxel nanosuspension using novel emulsification method by combining high speed homogenizer and high pressure homogenization," International Journal of Pharmaceutics, vol. 490, no. 1-2, pp. 324-333, 2015.

[33] S. E. Lee, S. F. Bairstow, J. O. Werling et al., "Paclitaxel nanosuspensions for targeted chemotherapy-nanosuspension preparation, characterization, and use," Pharmaceutical Development and Technology, vol. 19, no. 4, pp. 438-453, 2014.

[34] Y. Zhang, L. Jin, J. Liu et al., "Effect and mechanism of dioscin from Dioscorea spongiosa on uric acid excretion in animal model of hyperuricemia," Journal of Ethnopharmacology, vol. 214, pp. 29-36, 2018.

[35] G. Pilcer, F. Vanderbist, and K. Amighi, "Preparation and characterization of spray-dried tobramycin powders containing nanoparticles for pulmonary delivery," International Journal of Pharmaceutics, vol. 365, no. 1-2, pp. 162-169, 2009. 


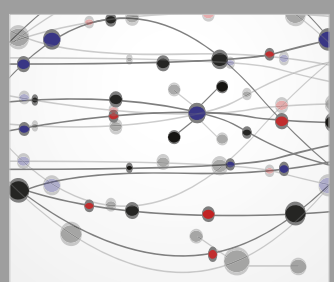

The Scientific World Journal
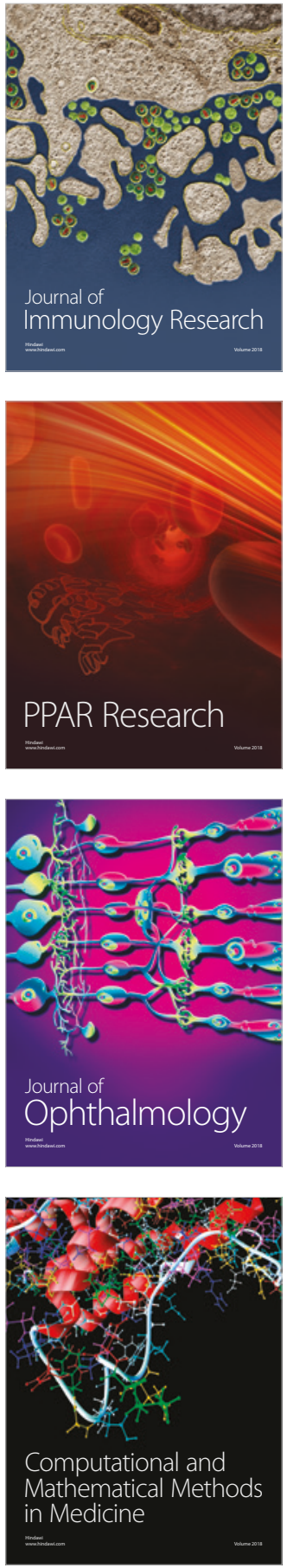

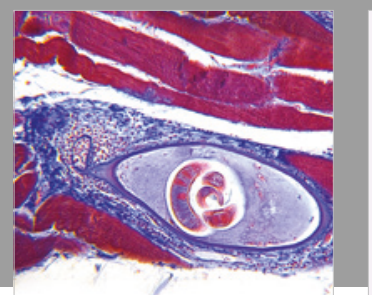

Gastroenterology Research and Practice

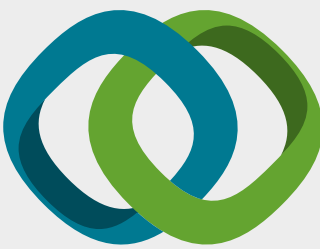

\section{Hindawi}

Submit your manuscripts at

www.hindawi.com
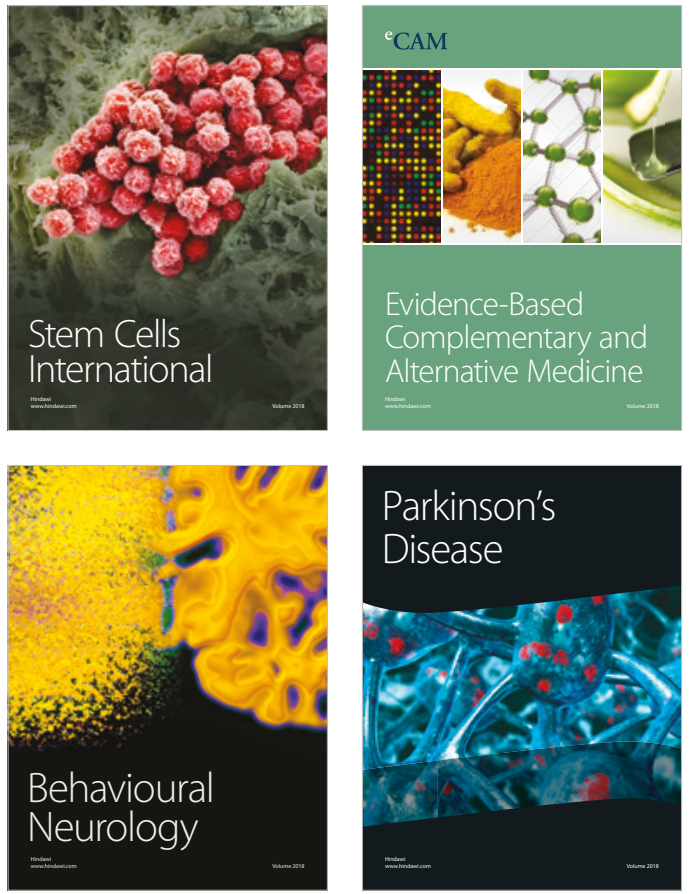

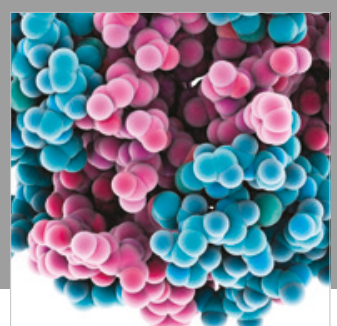

ournal of

Diabetes Research

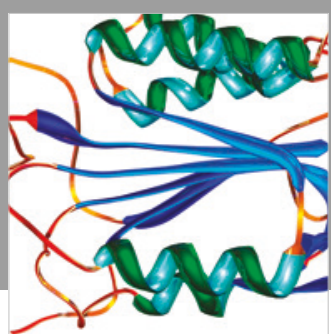

Disease Markers
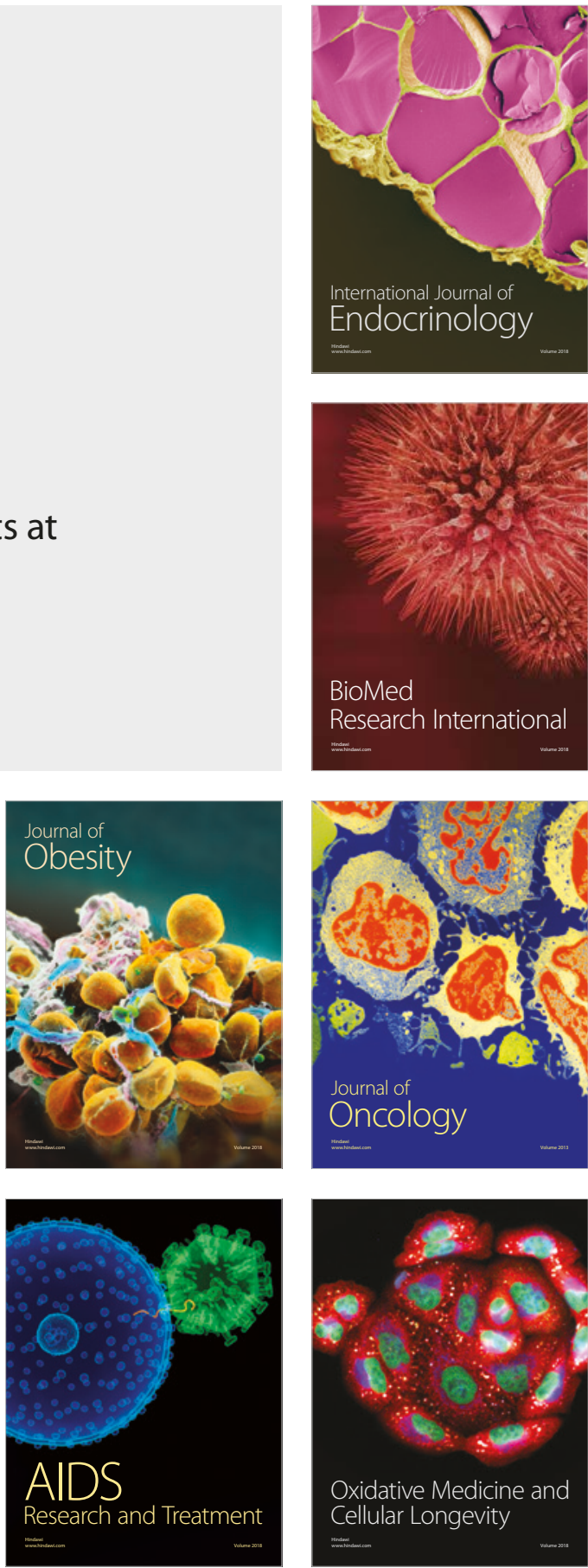